\title{
Algunos hitos en el devenir de la disciplina antropológica en Costa Rica: 1880-2015
}

\author{
María E. Bozzoli
}

Profesora emérita, Escuela de Antropología, Universidad de Costa Rica, San José, Costa Rica MARIA.BOZZOLI@ucr.ac.cr

Dedicatoria

Estudiantado y profesorado de la Escuela de Antropología, Facultad de Ciencias Sociales

Marzo-Mayo de 2015

Este documento de trabajo se escribe como base para una conferencia sobre el tema, solicitada por la directora de la Escuela de Antropología en 2015, Dra. Silvia Salgado. Considera ella que las nuevas generaciones necesitan refrescar sus conocimientos del devenir de la Antropología en Costa Rica; espero cumplir con ese propósito, al dar la conferencia y al facilitar este documento para consulta.

Los recuerdos de experiencias vividas en la antigua Facultad de Ciencias y Letras, en la Escuela de Ciencias del Hombre, en la Escuela de Antropología y Sociología, en el Departamento de Antropología y en la actual Escuela de Antropología involucran a muchísima gente, de la Universidad de Costa Rica y de otras instancias costarricenses y extranjeras, para la que solo es posible dar las gracias en forma general. Del mismo modo

Cuadernos de Antropología

Enero-Junio 2016, 26(1), 105-160

Recibido: 18-06-2015 / Aceptado: 27-05-2016 / Publicado: 28/06/2016

Revista del Laboratorio de Etnología María Eugenia Bozzoli Vargas

Escuela de Antropología, Universidad de Costa Rica

http://revistas.ucr.ac.cr/index.php/antropologia

ISSN 2215-356X

cC) (i) (-) Cuadernos de Antropología está bajo una licencia Creative Commons

Attribution-NonCommercial-ShareAlike 3.0

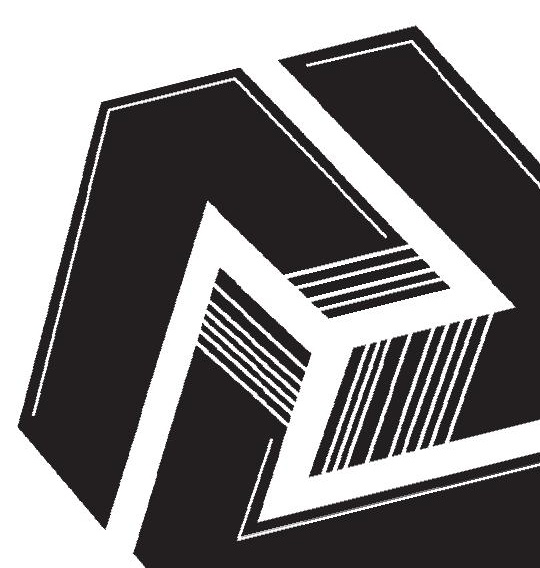


implícito, se agradece al estudiantado entre 1960 y 2005. Expreso gratitud a Felipe Calderón por la ayuda con la presentación del trabajo; colaboraron con información, fotografías, revisión, o de alguna otra manera, Floria Arrea, Margarita Bolaños, Giselle Chang, Mauricio Murillo, Eugenia Ibarra y Olga Echeverría. Esperamos con este trabajo estimular la identificación con y la continuidad de la actividad académica y las labores conexas que de ella se derivan para la acción en el medio social costarricense

Mi familia siempre me apoyó en mi trabajo. En su representación menciono a mi hija Leticia Wille Bozzoli y a mi hijo que nos acompaña desde otra dimensión, Álvaro Wille Bozzoli.

\section{Introducción ${ }^{1}$}

Este trabajo registra hitos que marcan el acontecer de la Antropología en el país, principalmente en la Universidad de Costa Rica; la metáfora del hito se basa en dos de sus sentidos, un mojón, poste u otro indicador que se pueda notar, que señala dirección o distancia en los caminos, o delimita el terreno. También es la persona, objeto o hecho clave dentro de un ámbito o contexto.

Estas notas sobre la historia de la disciplina antropológica en Costa Rica presentan algunos hechos y tendencias del devenir de la Antropología desde el final del siglo XIX hasta el año 2015. Parten del objetivo de traer a la memoria de los estudiosos del siglo XXI el devenir de la Antropología en el país. Se toma en cuenta la gran contribución de los estudios publicados por colegas que han documentado este tema; también están las memorias propias de la autora y documentos que conserva, tales como informes de labores de ella y de otras personas quienes coordinaron o dirigieron unidades. Una tercera fuente importante es la publicación de Margarita Bolaños Arquín y de María E. Bozzoli Vargas, del 2015, sobre el desarrollo de la Antropología en Centroamérica, obra de la cual se toman datos y párrafos pertinentes a la Antropología costarricense.

Los cursos universitarios de Antropología en Costa Rica se inician en 1941 con influencia de la Antropología europea y la del Hemisferio Occidental, esta última principalmente basada en dos de las corrientes antropológicas dedicadas; en ese tiempo, en gran medida, a la comprensión de las poblaciones indígenas antiguas y contemporáneas: la mexicana preocupada con las formas de articulación de los indígenas al devenir del Estado nacional, y la norteamericana del enfoque histórico-cultural boasiano. Con respecto a la investigación, desde finales del siglo XIX se pueden identificar contribuciones de parte de costarricenses; sin embargo, se puede afirmar que la Antropología en el país se desarrolla en especial de 1964 en adelante,

1 Este documento corresponde a la transcripción de la Conferencia Inaugural del I Ciclo 2015 e inauguración del nuevo espacio en el nuevo edificio de la Facultad de Ciencias Sociales, por parte de la Dr. María E. Bozzoli, impartida el miércoles 13 de mayo de 2015. Debido a su importancia, el Consejo Editorial de Cuadernos de Antropología decidió presentarlo dentro de esta edición. 
con el plan de bachillerato en la Sección de Ciencias del Hombre, y 1968, con el inicio de clases bajo la modalidad de Departamento, el cual amplía la vía para la profesionalización en la Universidad de Costa Rica. No obstante, en los decenios anteriores a las décadas de 1940 y 1950, en las que se puede vislumbrar el devenir posterior, hubo preocupación por explicar temáticas antropológicas, principalmente las que concernían a la población indígena del pasado y a la de esos años (Bozzoli, 2013; Martin, 1942).

Gradualmente desde mediados de siglo XX, aumentando en intensidad desde las décadas de 1960 y 1970, se dio la relación con los departamentos de Antropología de Centroamérica y México; precisamente, inspiradas en el desarrollo de esa conexión, Margarita Bolaños y María Eugenia Bozzoli plantearon etapas generales para ordenar lo acontecido en el desarrollo de la Antropología en la región centroamericana (Bolaños y Bozzoli, 2015). Los períodos propuestos para ese desarrollo han servido de guía para el presente ensayo; son útiles para ordenar una historia disciplinar que ha acumulado muchísimos datos y perspectivas desde el tiempo de origen hasta la actualidad; cada período refleja ciertos énfasis, y difiere del siguiente porque este agrega algo que no estaba en el anterior; por eso el paso de un período a otro no representa de ninguna manera una ruptura con los precedentes, pues siempre es posible descubrir o mostrar continuidades. Se han utilizado en el presente trabajo para ordenar lo que atañe al acontecer costarricense; los períodos son los siguientes:

1) Los estudios antropológicos y las construcciones de la identidad nacional. La indianidad y el mestizaje como preocupaciones principales: 1880-1945.

2) Los estudios antropológicos y la modernización de las sociedades rurales. Ladinización, integración, cambio social y modernización de las economías rurales tradicionales: 1945-1970.

3) Los estudios antropológicos de la violencia y de la lucha étnica y campesina, la violencia de género, el deterioro ambiental y el fracaso de las políticas de modernización e integración de las sociedades rurales: 1970-1985.

4) Los estudios antropológicos y las culturas populares; nuevas alternativas de poder; la economía informal; desarrollo sostenible: la sostenibilidad de los sistemas tradicionales de producción, el ecoturismo, y las alternativas locales de desarrollo.1985-2000.

5) Las preocupaciones y tendencias de la antropología, en el marco de la globalización como nueva revolución cultural de la humanidad: 2001-2015.

6) En las conclusiones se explicará por qué un nuevo período puede gestarse a partir de 2015.

Retomando lo dicho anteriormente sobre los cursos universitarios, estos se establecieron siguiendo las ramas de la Antropología de orientación boasiana, una de las corrientes más influyentes en Estados Unidos y Latinoamérica, la que incluía la Antropología Física - ahora Antropología Biológica- y los campos culturales, que eran Arqueología, Etnografía, Etnología y Lingüística. La mexicana se apegaba a este esquema. Pero también hubo influencia en un inicio del indigenismo, por su relación con la investigación antropológica, pues en general era visto como la corriente de acción y pensamiento para resolver lo que se concebía como problemas en las comunidades indígenas para participar del desarrollo socioeconómico del país. 
Las visiones favorecedoras de la convivencia menos conflictiva con la población aborigen se han agrupado en indigenismos de distintas orientaciones; entre estas la académica, que se relaciona más directamente con la Antropología. La evolución del pensamiento antropológico en el tema indigenista se vincula con el devenir del Museo Nacional de 1940 a 1960. Sin embargo, no solo el indigenismo podía ser visto como actividad para el Museo, sino también que en el campo indígena los vestigios del pasado son patrimoniales, y a esa institución se le encarga la custodia y conservación de ese patrimonio cultural. La salvaguarda del patrimonio indígena también ha sido tema universitario.

El primer antropólogo profesional costarricense fue Carlos Aguilar Piedra (25 de agosto de 1917 - 31 de marzo de 2008); obtuvo su título de maestro en Ciencias Antropológicas en México en 1946; María Eugenia Bozzoli Vargas (26 de mayo de 1935-); lo siguió con los títulos de bachillerato y maestría, de Kansas, EE.UU, en 1956 y 1958, respectivamente (posteriormente el doctorado en 1975, en Georgia). Aguilar también hizo una pasantía por un año en Kansas, setiembre 1946 - setiembre 1947.

De los años de la década de 1960 en adelante se diversifican los grupos humanos estudiados (grupos nacionales, mestizos, afrodescendientes, y otros de inmigración latinoamericana, europea y asiática), pero los indígenas permanecen en los estudios hasta el presente.

Desde 1960 (véase por ejemplo: Stone, 1961), pero particularmente en el siguiente, se abordan los procesos de transculturación de los indígenas, la modernización de sus comunidades y las del campesinado tradicional no indígena. Se estudia el papel del Estado en los proyectos de modernización del agro, así como el de las agencias como el Instituto Indigenista Interamericano, los programas del Punto IV, la Alianza para el Progreso, y otras entidades para el desarrollo. El país se conecta mediante la carretera interamericana con el resto de Centroamérica. El Caribe empieza a ser tomado en cuenta en los estudios de campo.

Como se mencionó, los programas de enseñanza de la Antropología se consolidan a partir de 1964. A 1975 se había llevado a cabo investigación en el Museo Nacional y en la UCR, suficiente como para atraer la sede del "I Congreso Centroamericano de Antropología y Patrimonio" en 1975. Se promovieron otros encuentros académicos de carácter internacional posteriormente. Sin embargo, un antecedente importante en el país de este tipo de encuentros fue, en 1958, el XXXIII Congreso Internacional de Americanistas, organizado por el Museo Nacional y la Universidad de Costa Rica.

El Departamento de Antropología y la Escuela posteriormente han mostrado sus avances en encuentros nacionales y con participantes del resto de Centroamérica y de otros países. Son ejemplos el "I Encuentro Centroamericano de Antropología" celebrado en 1988, en Turrialba, Costa Rica; los talleres promovidos por el Plan Centroamericano de Antropología entre 1989 y 1992; los diez congresos de la Red Centroamericana de Antropología (RCA) realizados entre 1994 -ese año en Costa Rica- y 2015, en los otros países 
centroamericanos o México, pero con gran participación costarricense (el décimo fue celebrado en Yucatán en marzo de 2015); el simposio y los congresos sobre indígenas de Costa Rica (1984, 1995, 2000) y los congresos nacionales de Antropología (1085, 1999, 2003, 2005).

De lo más reciente, del 2000 en adelante, se cuenta con los avances en la formación en estudios de posgrado. En 2015 se realiza el trámite de creación de un Centro de Investigaciones Antropológicas en la Escuela de Antropología de la UCR.

A continuación se resume el acontecer de la Antropología según las etapas o períodos ya mencionados; se hace referencia a hechos y autores a manera de ejemplos del devenir de la disciplina.

\section{Surgimiento}

Construcciones de la identidad nacional, con la indianidad y el mestizaje como preocupaciones principales (1880-1945).

\section{Características generales}

Entre las fechas de acontecimientos de interés para caracterizar el periodo se encuentran:

1887 Creación del Museo Nacional, director Anastasio Alfaro;

1891 Excavaciones arqueológicas por don Anastasio Alfaro en el sitio de Guayabo de Turrialba;

1917 Sección de Antropología e Historia creada en el Museo Nacional;

1930 El Museo Nacional, en su carácter de institución educativa, apoya enseñanza primaria y secundaria, director José Fidel Tristán;

1940 Creación de la Academia de Geografía e Historia y de la Universidad de Costa Rica;

1941 Carlos Aguilar va a estudiar en la Escuela Nacional de Antropología e Historia de México, se gradúa en 1946;

1944 Museo Nacional es dependencia de la UCR, hasta 1952.

Las bases de los estudios antropológicos surgen de las antropologías de Europa, Estados Unidos y México, quienes habían emprendido las tempranas investigaciones de las poblaciones indígenas (biológicas, arqueológicas, etnográficas, etnológicas, lingüísticas); de la Historia, con mayor antigüedad como campo de estudios que las otras ciencias sociales, y del indigenismo. En relación con el acontecer indigenista centroamericano, en general, las tendencias son aplicables a Costa Rica: 
De la relación del indigenismo con la Antropología en este período, se pueden señalar los debates intelectuales sobre la inserción de lo indígena, o del mestizaje, en los devenires nacionales; el impulso a la investigación y a la docencia sobre la temática indígena, a fin de que sirvieran de orientación a las políticas indigenistas de los Estados; el empleo de profesionales de la disciplina en entidades ligadas a lo indígena como los museos, institutos y juntas; su participación, remunerada o ad honorem, en comisiones, juntas, organización de congresos u otras formas de asesoría;... la creación de órganos de publicación indigenistas en los que los trabajos de distintos profesionales fueron bienvenidos, y otras formas de relación (Bolaños y Bozzoli, 2015).

En Costa Rica, los indígenas no fueron una preocupación importante para la intelectualidad de finales del siglo XIX ni de los primeros decenios del XX, salvo para funcionarios y estudiosos en el Museo Nacional, para quienes estaban cercanos a ellos, o para artistas como pintores y escultores. En general, en el pensamiento cultivado costarricense a las poblaciones originarias no se las consideraba como una amenaza al mito de la sociedad blanca, pues aquellas "puras" y "en proceso de extinción” se encontraban muy alejadas de "la meseta central" que era la medida de la nación, mientras que los descendientes de las poblaciones nativas que habitaban "la patria", el Valle Central, estaban muy lejos para esa época de reclamar su ascendencia indígena. Dentro de los pocos trabajos por costarricenses que se cuentan para el periodo, tenemos los de los naturalistas y pioneros de los estudios antropológicos, Anastasio Alfaro y José Fidel Tristán, quienes ejemplifican el esfuerzo autodidacta de la época. Sobre Alfaro, su título universitario fue de notario e hizo otros estudios diversos. Tuvo fuerte inclinación por la Historia Natural y eso lo hizo idóneo para ser el fundador y Director del Museo Nacional de Costa Rica en 1887, institución desde la cual hace aportes en ese campo. Coleccionó objetos arqueológicos para el Museo, excavó en Guayabo, preparó exposiciones, escribió poesía y ensayo, principalmente para niños, para enseñarles sobre ciencias y temas costarricenses. Les escribió una novelita (Alfaro, 1923) con personajes indígenas en la cual recrea su particular visión de lo que pudo haber sido la sociedad indígena por la época de la Conquista, y precisamente dice que hilvanó el cuento "para despertar el cariño por nuestros antiguos indios, ante un auditorio numeroso de cabecitas infantiles". Sobre José Fidel Tristán, su título fue de profesor en Física y Química, obtenido en Chile en 1900; sus contribuciones a la Arqueología han sido objeto de estudio por parte de Myrna Rojas y Gabriela Madrigal (véase Tristán [2007]) y sus contribuciones a la Etnografía por parte de María E. Bozzoli (2013).

En Costa Rica, como se suponía que predominaba el tipo caucásico, la equivalencia de raza con cultura resultaba en la propuesta de que entre más "puro el tipo", más pura y homogénea la cultura nacional (Bolañosa, 2001). En la visión de Corrales (1999) entre las características de la Arqueología del período están las siguientes:

El hecho de que los grupos indígenas fueran tomados en cuenta de una manera marginal en la construcción de una identidad nacional llevó a que el Museo Nacional se orientara más a la exhibición de los objetos precolombinos desde el punto de vista artístico y carente de profundidad histórica, al dominar una mentalidad coleccionista. La incorporación del pasado precolombino dentro de la educación formal se dio 
de una manera plana y simplista. Era un pasado 'inventado', pero no con el propósito de glorificarlo para producir una identificación con el pasado común (...) Esta visión del pasado de Costa Rica reforzó la historia oficial que establecía el origen de la identidad costarricense con el arribo de los españoles. Los pocos y 'primitivos' indígenas de acuerdo con esta visión siguieron siendo excluidos de la identidad nacional (...)".

En los primeros decenios del siglo XX hubo preocupación por explicar, por un lado, la distancia entre el extraordinario desarrollo de las culturas antiguas o prehispánicas y la "decadencia cultural" del indio del presente, y por otro, el nacimiento de la sociedad mestiza. El "problema del indio" estimuló la creación de carreras en Antropología en otros países; en Costa Rica no se vio como fundamental dado que se confiaba en la asimilación o en el inexorable "progreso" de la población minoritaria indígena del país. Por lo tanto, una carrera en Antropología, si era para atender problemas o temáticas indígenas, no tenía razón de ser .

En los inicios del siglo XX, la cultura nacional no se mostraba muy preocupada por establecer puentes entre el pasado precolombino y el contemporáneo; por el contrario, las preocupaciones apuntaban a consolidar las raíces europeas de la población. Fue en 1940 que la Sociedad de Geografía e Historia (posteriormente Academia de Geografía e Historia de Costa Rica) y la Universidad de Costa Rica, creadas a distancia de un mes una de la otra, abordaron, aunque no intensivamente, el estudio de lo indígena, principalmente con base en el estudio de los textos históricos. Fue más intensivo el estudio de la historia nacional republicana. Otros intelectuales que escribieron en revistas de la época reflejaron los conceptos de 'raza', de 'cultura', y algunos más relacionados con estos, tal como lo ha analizado la historiadora Patricia Alvarenga .

Costa Rica, por otra parte, considerada como de origen español principalmente (ni mestiza, ni ladina), se preocupó poco de sus raíces indígenas y las de otros orígenes culturales; en lo indígena se admiró el arte reflejado en las artesanías "de lujo" (oro, lítica, cerámica); se admitía la superioridad de mayas, aztecas e incas como etapa civilizatoria que no estaba presente en el país. Con respecto a la situación colonial, no se enfatizó en la resistencia indígena, sino en una democracia y homogeneidad cultural costarricenses surgidas de relaciones armoniosas.

En relación con la influencia mexicana, las tesis de José de Vasconcelos sobre el mestizaje se conocieron, por ejemplo, en las publicaciones de Joaquín García Monge (Lara, 2004), quien retrata con realismo el cotidiano sufrimiento del indio y del campesino .

Otra fuente de influencia en lo que se podría denominar pensamiento antropológico del período fue la Escuela Nacional de Antropología de México. Desde su fundación, en 1938, había asumido el compromiso de formar antropólogos latinoamericanos. Daniel Rubín de la Borbolla, casado con Sol Arguedas, costarricense, graduada en Historia de la ENAH, viene a Costa Rica para ofrecer dos becas para estudiar Antropología en México. De acuerdo con el testimonio de Carlos Aguilar Piedra, primer arqueólogo centroamericano graduado en la ENAH, 150 solicitudes fueron presentadas. El becario Aguilar partió en 1941 para realizar sus estudios. El otro costarricense becado fue Ricardo Soto Guevara, quien se casó con una 
hija del dirigente sindical Lombardo Toledano. Ambos costarricenses fueron patrocinados por la Fundación Rockefeller, institución que estaba comprometida con el desarrollo de la antropología en el nivel continental (ENAH, Anuario 1944) (Bolaños y Bozzoli, 2015).

\section{El contexto sociopolítico, 1880-1945}

Los historiadores sitúan el auge y crisis de las repúblicas agroexportadoras a partir de los años de 1870 hasta 1945 (Fonseca, 1996), lo cual es coincidente, excepto por la década inicial, con el período que aquí se presenta como inicio del desarrollo de la Antropología. Sin embargo, los historiadores en Costa Rica también suelen considerar 1880-1930 como una etapa avanzada de la economía exportadora del café y señalar en ella diferentes procesos de cambio provocados por la influencia liberal. Uno de estos trabajos es el de Florencia Quesada Avendaño (2007), quien afirma "en San José, las élites liberales, sobre todo a partir de 1880, promovieron la transformación de la ciudad acorde con su ideología de progreso, con el propósito de higienizarla y al mismo tiempo 'civilizarla' (p. 281). Desde la Reforma Liberal hasta el fin de la Segunda Guerra Mundial, el desarrollo fue "hacia afuera" y se basó en el café y el banano principalmente. Estados Unidos fue principal mercado para la exportación. Los inversionistas alemanes fueron importantes en la producción de café. La "Reforma Liberal", apoyada por conservadores y liberales, favoreció el paso de tierras baldías a manos privadas. Esto tuvo efectos perjudiciales para las comunidades indígenas (Bolaños, 1998). Las condiciones de vida de los trabajadores en las plantaciones bananeras provocaron protestas sociales, y también hubo paros y huelgas obreras creando las condiciones para la consolidación del partido comunista.

\section{Encuentros académicos}

La celebración del I Congreso Indigenista Interamericano, realizado en 1940, en Pátzcuaro, y la subsecuente creación del Instituto Indigenista Interamericano dieron lugar a la creación del Instituto Indigenista (al parecer solo se encargó de mantener correspondencia con entidades indigenistas) y a la Junta de Protección de la Razas Aborígenes de la Nación (Junta Indigenista) en Costa Rica en 1945. Esta Junta fue especialmente del interés de la Dra. Doris Stone y de un grupo que ella lideró, el cual incluía personas en San José que fueron miembros de la Junta, y de maestros y maestras que la Junta contrató para las primeras escuelas indígenas creadas en Buenos Aires de Puntarenas. Es de interés que el Instituto Indigenista Interamericano también promoviera la profesión antropológica. En el acta final del I Congreso Indigenista Interamericano, quedaba explícito el interés de los participantes de formar antropólogos profesionales en América Latina:

Recomienda: Al Instituto Indigenista Interamericano, promueva el establecimiento de escuelas o departamentos de antropología para el estudio de la población indígena y para la preparación de los peritos 
en asuntos indígenas, aprovechando en cada país las instituciones docentes que ya existan y ampliando los cursos en la medida que sea necesario. En caso de que un país no pueda por el momento establecer una escuela de antropología, se sugiere que envíe alumnos becados a las escuelas ya existentes. Que utilicen de preferencia a los antropólogos y peritos que hayan estudiado en estas escuelas para emplearlos en sus respectivos departamentos de acción social (Suplemento del Boletín Indigenista. 1948; Bolaños y Bozzoli, 2015).

Las personas vinculadas con la Antropología o con asuntos indígenas asistieron a encuentros en México, tanto para tratar asuntos relacionados con políticas indígenas -como en Pátzcuaro en 1940- o bien, para estudios arqueológicos. Del 27 de abril al 1 de mayo de 1942, en Tuxtla Gutiérrez, Chiapas, se celebró la "Segunda Mesa Redonda de la Sociedad Mexicana de Antropología", para discutir "el problema Olmeca", la cual contó con la presencia del especialista Jorge Lines Canalías, profesor de los cursos de Etnología y Prehistoria de la Facultad de Filosofía y Letras de la Universidad de Costa Rica. El título de su ponencia fue "Un baby face en Costa Rica" (Lines, 1942).

Con respecto a Jorge Lines, se insertan a continuación datos consignados en una Guía de la UCR (Martin, 1942): En la Escuela de Letras y Filosofía, una sección era de Filología, otra era de Historia. Esta última comprendía: Historia de la Civilización, Etnología, Geografía y Sociología. Se menciona la Etnología como una de las Ciencias en que se capacitará para la enseñanza superior. Y para el futuro:

Aparte de la creación de bibliotecas y laboratorios de investigación, de la organización de seminarios, la Escuela establecerá un Instituto de Investigaciones Arqueológicas en la Sección de Historia, que, aparte de contribuir al estudio de esta ciencia, prepare para la dirección y administración de los museos (Martin, 1942, p. 99).

Sobre la cátedra de Etnología, su descripción era:

Cuatro años. Una hora diaria. (Profesor don Jorge Lines). Primer año: Etnología y prehistoria de América. Segundo año. Conquista y colonización. Tercer año: Historia de América independiente. Cuarto año: Historia documentada de Costa Rica (Martin, 1942, p. 102).

Sobre el profesor, consigna:

Profesor de Etnología y Prehistoria de América. Secretario de la Escuela de Letras y Filosofía. Don Jorge A. Lines. Nació en Barcelona, España, el 29 de diciembre de 1891. Estudios primarios en San José de Costa Rica; secundarios en Mount Saint Mary's College, Emmitsburgh, Maryland; diploma del curso clásico en la Riverview Military Academy, de Poughkeepsie, New York; en Europa, estudios privados 
políglotas y antropológicos; Delegado de la Universidad de Costa Rica al Congreso de Tuxtla-Gutiérrez, Chiapas, México, 1941; autor de varias pequeñas monografías sobre la etnología y arqueología de Costa Rica, entre ellos, Los Altares de Toyopán, Una Huaca en Zapandí, Notes on the Archaeology of Costa Rica, Sukia: Tsúgür o Isogro, Cabezás-retrato de los huetares, Crónica de nuestro Conquistador Juan Vásquez de Coronado, una hacha monolítica de Río Cuarto, el Arte aborigen de Costa Rica, etc (Martin, 1942, pp. 105-106).

\section{Obras representativas o influyentes}

Sin duda una de las publicaciones, tanto representativas de la temática indígena del período, como también una muy consultada, es la primera edición de la Bibliografía Antropológica Aborigen de Costa Rica, de Jorge A. Lines. Detalla 1262 cédulas bibliográficas de textos sobre el indígena costarricense, en la literatura del país y del extranjero. Las fechas van de 1502 a 1940. La bibliografía incluye lo publicado en arqueología, cartografía, etnología, geografía, historia y lingüística. Uno de los datos interesantes, para imaginarse la época, es el listado de bibliotecas del país que consultó, públicas y privadas. La obra fue publicada en 1943 por la Universidad de Costa Rica. Posteriormente Lines la actualizó hasta incluir lo publicado en 1964 (Lines, 1967).

\section{Profesionalización}

La modernización de las sociedades rurales. ladinización, integración, cambio social y modernización de las economías rurales tradicionales: 1945-1970.

\section{Características generales}

Entre las fechas de acontecimientos de interés para caracteriza el periodo se encuentran:

1949 Se traslada el Museo Nacional al Cuartel Bella Vista, actual sede (2015). Doris Z. Stone, primera presidenta de la Junta Administrativa, hasta 1967.

1957 Reforma universitaria.

1962 Carlos Aguilar y María Eugenia Bozzoli iniciaron cátedras de Arqueología de América, Arqueología de Costa Rica y Antropología Cultural, en la licenciatura de la Escuela de Historia y Geografía. Se creó la Comisión de Ciencias del Hombre. Se creó el Centro de Estudios Sociológicos y Antropológicos.

1963 Sección de Ciencias del Hombre. 
1964 El 14 de diciembre se autoriza el Bachillerato Universitario en la Sección de Ciencias del Hombre.

1966 Aprobación del plan de estudios del Bachillerato en Ciencias del Hombre; se autoriza el Bachillerato en las tres disciplinas, Antropología Sociología, Psicología.

1967 Se aprueba, en diciembre, el cambio de Sección a Departamento de Ciencias del Hombre, con tres Secciones: Antropología, Sociología, Psicología.

1968 El Depto. de Ciencias del Hombre inicia clases. Tres profesores: María E. Bozzoli, Carlos Aguilar y Janina Bonilla. Otros profesores en el énfasis de Antropología, como el Prof. Víctor Arroyo, y el Prof. Ronald Chaves, pertenecían a otras unidades académicas. Se inauguró el Laboratorio de Arqueología.

1970 La Sección cuenta con 7 profesores en propiedad. Se crea la Comisión para estudiar "Posibilidades de trabajo para los graduados de Ciencias de Hombre”.

A partir de la década de los 1950, los estudios sociales fueron influenciados por la sociología marxista latinoamericana. El estudio de las estructuras sociales cobró relevancia para explicar tanto la explotación como la supervivencia de las poblaciones indígenas y sus culturas.

Una nueva etapa del desarrollo socioeconómico había comenzado después de la Segunda Guerra Mundial y los programas gubernamentales, con la cooperación norteamericana, promovían la superación del "atraso" económico y cultural por medio de políticas de incorporación o integración de las poblaciones rurales, incluidas las que tenían fuerte tradición indígena.

Una de las influencias sentidas en Costa Rica desde mediados del siglo XX fue la presencia de profesionales no antropólogos que habían recibido materias antropológicas en México. Juan Comas (1969) explica la importancia de formar profesionistas no antropólogos. En cuanto a la formación del magisterio, se ofrecían cursos patrocinados por la Organización de Estados Americanos, OEA y la Unesco, a los cuales asistían becarios de toda América Latina. También fue importante la asistencia de los educadores al Centro Regional de Educación Fundamental para América Latina (CREFAL), donde recibían Antropología Social y Aplicada (Comas, 1969). El Programa Interamericano para el adiestramiento de posgraduados en ciencias sociales aplicadas, organizado por la OEA, en colaboración con la Escuela Nacional de Antropología de México de 1959 a 1963, es otro importante ejemplo de esa cooperación e influencia de la antropología mexicana de manera indirecta. Igualmente, Comas (1969) se refiere al interés de la Facultad de Medicina de la Universidad Autónoma de México, UNAM por la enseñanza de cursos de Antropología Física y Sociocultural de 1958 en adelante. A la Antropología se le asigna un papel fundamental en la preparación de otros profesionales, como los de Derecho y Economía, Historia, Diseño Industrial, Enfermería y Ciencias Políticas.

El resultado de impartir Antropología a otras profesiones fue que algunos quienes estudiaron en México se sensibilizaron a las materias antropológicas y sirvieron de apoyo a los pocos antropólogos profesionales, que a partir del decenio de 1960 trataban de establecer la carrera y centros de estudio. 
El desarrollo profesional de la Antropología después de concluida la II Guerra Mundial se relaciona con el desarrollo de la Antropología norteamericana y mexicana. Aguilar y Bozzoli obtuvieron títulos en México en el caso de Aguilar, y en los Estados Unidos en el de Bozzoli, de manera que las características con que se perfila la Antropología están estrechamente relacionadas con esas dos importantes tradiciones antropológicas, que incluían además la corriente indigenista en la mexicana y los estudios de comunidad en la Antropología norteamericana (Adams y Bolaños, 1996).

Las investigaciones antropológicas norteamericanas, o de nacionales con esa orientación, buscaron entender el cambio social desde diversos puntos de vista culturales, en los campesinos -indígenas y mestizos-, inmigrantes y la clase media. Los estudios de comunidad (localidades, barrios, poblados rurales o urbanos) fueron abordados etnográficamente. La otra tendencia que se inició en esta época fue la influencia de la Sociología latinoamericana, la cual estaba influida por la revolución cubana y las teorías del desarrollo dependiente de América Latina . Los estudios antropológicos influidos por esta sociología, marxista, y también por la crítica de los antropólogos mexicanos al indigenismo de Estado, se oponían a las interpretaciones denominadas culturalistas y funcionalistas norteamericanas. Las críticas a la Antropología norteamericana no distinguían entre las corrientes teóricas que en la época enmarcaban los estudios y que eran objeto de discusión en EE. UU, por ejemplo, las que se referían a la evolución cultural (estaba en boga debatir entre el enfoque de evolución universal de Leslie White y multilineal de Julian Steward), las que eran propias de la extensa escuela de cultura y personalidad, las del funcionalismo británico y del particularismo histórico, etc. Estas corrientes, así como otras europeas, se explicaban en el curso de Antropología Cultural impartido en la licenciatura en Historia y en el bachillerato en Antropología de las décadas de los años sesenta y setenta; y en años posteriores, en cursos de teorías antropológicas. En cuanto a la influencia mexicana, en la opinión de Bolaños (2001a) la crítica al indigenismo de la Antropología latinoamericana, influenció la praxis antropológica costarricense.

Hubo un abordaje más de tipo histórico hasta los años cuarenta y cincuenta, pero gradualmente se fueron introduciendo los enfoques relacionados con la Antropología como campo autónomo de estudios y los de influencia de otras ciencias sociales. En el Departamento de Historia y Geografía de la UCR, las visiones más antropológicas estuvieron representadas por don Carlos Meléndez Chaverri, quien había trabajado en el Museo Nacional; entre 1953 y 1960 se desempeñó en la jefatura de la Sección de Antropología e Historia. Meléndez influyó para incluir Antropología Cultural y Arqueología de América y de Costa Rica en el programa de licenciatura en Historia. Él estaba al día en desarrollos en ambas materias. Las cátedras salieron a concurso en 1961, y Carlos Aguilar y la autora resultaron escogidos en ese concurso, con el rango de profesores titulares de ellas. El mismo Mélendez había sido discípulo de Jorge Lines en la antigua escuela de Filosofía y Letras. La autora notó que quienes habían sido discípulos de Lines tenían una orientación favorable a los indígenas y al estudio de su cultura. Tanto en Arqueología como en Etnología dio los cursos don Jorge Lines a partir de 1941, hasta 1961. Don Jorge se asoció con el Museo Nacional durante los años 1940; formalmente se desempeñó (Ad honorem) como director del Museo en 1951 y 1952. 
En los años de la década de 1960, la Universidad venía de la Reforma Universitaria de 1957, estaba empeñada en modernizarse; esto fue paralelo a un interés de otras universidades latinoamericanas, interesadas en incorporar tendencias que se daban en el desarrollo universitario de Europa y Estados Unidos en ese tiempo. En la perspectiva más amplia, la modernización universitaria se miraba como manera de cooperar con el desarrollo de estos países. Se dio apoyo a Rodrigo Facio y a quienes le siguieron en llevar a su final la gran reforma universitaria. Se puede ver en la ayuda que se dio para enviar profesores al extranjero, establecer el sistema de tiempos completos para profesores, y construir edificios. Pero también los gobiernos aplicaron el paradigma de la modernización a otras instituciones públicas, como lo concerniente a salud, planificación, y otras.

Por la parte de las otras ciencias sociales, especialmente de los años 60 en adelante, es destacable la participación de Eugenio Fonseca Tortós, sociólogo (Bozzoli, 2000), y la de Claudio Gutiérrez Carranza, filósofo. Ambos estaban en el paradigma de las ciencias sociales como Ciencias de la Conducta Humana, que fue la idea general para establecer alguna unidad académica con esa orientación, lo que en el período de don Claudio como Decano de Ciencias y Letras lo llevó a establecer primero la Comisión de Ciencias del Hombre con miembros de Ciencias Económicas, Psicología, Sociología y Antropología. De la Facultad de Ciencias y Letras estuvimos Gonzalo Adis Castro, y Pierre Thomas Claudet, psicólogos, Eugenio Fonseca Tortós y el Padre Benjamín Núñez, sociólogos, y Carlos Aguilar y la autora por Antropología. De la Comisión salió la idea de creación de la Sección de Ciencias del Hombre para que se pudiera impartir cursos para acreditarlos en algún programa, invitar profesores, y otras funciones de los departamentos. La Sección incluía Psicología, Sociología y Antropología, y pasó finalmente a ser el Departamento de Ciencias del Hombre. El decano, más tarde rector de la UCR, Claudio Gutiérrez, se doctoró en Filosofía en Chicago y ahí se había familiarizado con nuevas tendencias en las Ciencias Sociales, y tenía interés en que la Facultad estableciera esas disciplinas según las nuevas modalidades. Fuimos avanzando poco a poco porque la Universidad realmente era limitada en recursos económicos. Pero vino alguna ayuda de fundaciones, como la Ford, para crear tiempos completos en lo que fue, hasta el tercer Congreso Universitario, la Facultad de Ciencias y Letras.

En la Reforma Universitaria (1957), la Universidad de Costa Rica había incorporado los estudios de las Ciencias Sociales en los niveles básicos, por ejemplo, Sociología en el primer nivel de los Estudios Generales; en los denominados cursos de Área, como de segundo nivel, cursos introductorios de Sociología y de Economía. En el de Sociología estaban incorporados temas de la Antropología Cultural de ese tiempo, como por ejemplo, los de "cultura y personalidad". En la Facultad de Ciencias y Letras, el decano Claudio Gutiérrez Carranza promovió la inclusión de la Antropología, la Sociología y la Psicología, según las últimas tendencias en el desarrollo de esas ciencias, muy basadas en la investigación empírica o en sus paradigmas de Ciencias de la Conducta. La apertura de la carrera de Antropología se facilitó desde 1962 cuando el decano Gutiérrez organizó la Comisión de Ciencias del Hombre, para asesorar en las políticas por seguir para docencia e investigación. En 1962, el Consejo Universitario autoriza la creación del Centro 
de Estudios Sociológicos y Antropológicos (acta del Consejo Universitario, no.1211 del 21 de mayo de 1962); estaba vigente en 1967 con M. E. Bozzoli como coordinadora. La Sección de Ciencias del Hombre fue creada posteriormente para ofrecer cursos con créditos. Finalmente, se estructura el bachillerato: se dio autorización a la sección de Ciencias del Hombre, que había empezado a funcionar en 1963, para ofrecer este grado para las disciplinas de la Antropología, Sociología y Psicología, en la Sesión No. 140, Art. 2 del Consejo Universitario, el 14 de diciembre de 1964; se aprueba el plan de estudios de bachillerato para las tres disciplinas por parte de la Comisión de Planes y Programas de la Universidad en 1966 (Bonilla, 1994). En los cursos de bachillerato, los programas de las materias incluían lecturas y discusión de lo producido en el país, que a esas fechas era una producción muy limitada. Las contribuciones escritas con base en investigaciones se empezaban a acumular gradualmente por parte de los profesores iniciales graduados fuera del país, y por supuesto, los aportes mayores vendrán cuando se fueron agregando a la unidad académica profesores con títulos en Antropología y con el desempeño de los graduados de estos primeros planes en períodos posteriores. Los contenidos de los cursos incluían bibliografía pertinente producida en otros países sobre los temas tratados. El objetivo principal del bachillerato fue proporcionar a los estudiantes una base sólida de conocimientos que les permitiera realizar estudios posteriores para especializarse y profesionalizarse, con una licenciatura, como era el sistema de la UCR, o con maestrías y doctorados fuera de las fronteras nacionales. Se transmitía, por medio de las materias que se enseñaban, que la profesión antropológica estaba basada en que el profesional fuera un investigador, si bien completar las destrezas para esto iba a depender de títulos que aún no se podían planificar; una de las razones consistía en que los recursos para pagar profesores eran muy limitados en ese momento.

Al iniciarse el bachillerato, se contaba con tres profesores con títulos en el nivel de maestría en Antropología; por supuesto, las materias que no eran de Antropología, pero necesarias para la base general del bachillerato, contaban con profesores graduados, con licenciaturas, maestrías o doctorados, en esas otras disciplinas. El programa, planeado para 4 años de estudios incluía, en las materias generales, letras, ciencias naturales, ciencias sociales y metodología; los cursos específicos eran Antropología General, Cultural, Biológica, Lingüística, Arqueología y Etnología. Los cursos eran anuales. El Departamento de Historia y Geografía ofrecía cursos de interés específico para la Antropología; y ya había investigaciones que llevaban a cabo algunos profesores; en las Facultades de Medicina y Microbiología se realizaban estudios de interés para la Antropología Física. Al definirse el Departamento en 1968, se amplió el profesorado (Maestras Claudine Van Gyseghem, de Bélgica, Janina Bonilla, graduada en México, Dr. Ronald Cháves, geólogo con estudios de Paleontología en Italia), pero no fue sino hasta 1975 que fue posible dar el paso a la licenciatura, al contarse con más recursos humanos académicamente preparados en las ramas de la Antropología.

La Sección tuvo profesores invitados extranjeros para dar cursos cortos. Pero otros profesores estuvieron durante el año. Entre 1967 y 1968, el Dr. Joseph Spielberg, de la Universidad de Michigan en East Lansing, impartió los cursos de Etnología de América y de Métodos de Investigación. De 1970 a 1971, el profesor invitado fue el Dr. Dwight Heath, de la Universidad Brown de Nueva Jersey. También impartió Etnología de América y Métodos de Investigación. El curso de Etnología, tanto el impartido por Spielberg 
como el impartido por Heath (también dieron el curso M. E. Bozzoli y J. Bonilla), enfatizaba en los aspectos sociales y culturales de las sociedades contemporáneas de América Latina. El Dr. Ransford Pyle, de la Universidad de Florida, enseñó el Seminario en Lingüística en 1971 Al final de 1967, se aprobó, por parte de la Facultad de Ciencias y Letras, el proyecto de convertir a la Sección de Ciencias del Hombre en Departamento, con las Secciones de Antropología, Sociología y Psicología. En 1968, se inauguró el Laboratorio de Arqueología.

Se mencionó antes que la antropología mexicana tuvo influencia en el período anteriormente tratado (1880-1945). En este, de 1945 a 1970, se puede señalar que desde la creación del Departamento de Antropología de la Universidad de Costa Rica en 1967, para iniciar docencia en 1968, la antropología mexicana influyó también. Carlos Aguilar, graduado de arqueólogo de la ENA (luego ENAH) en 1946, fue uno de sus fundadores junto a María Eugenia Bozzoli, quien siendo discípula de Carlyle S. Smith, a su vez discípulo de discípulos de Boas, en la Universidad de Kansas tuvo la oportunidad de estudiar los aportes de la antropología mexicana. Por la parte lingüística, el Lic. Víctor Arroyo Soto, quien había estudiado en la Escuela Nacional de Antropología e Historia de México, de 1950 a 1953, dio los primeros cursos de Lingüística .

En 1969, la mexicana Eugenia López Casas, casada con uno de los médicos costarricenses formados en México, se integra al grupo de estudiantes del recién abierto Departamento. La Maestra Janina Bonilla, graduada en México, ya formaba parte de este. La conexión mexicana continuará en el período siguiente; por ejemplo, uno de los bachilleres, Oscar Fonseca, alumno de Arqueología, va a México a estudiar restauración en un programa de la OEA. Otra importante colaboradora, en el siguiente período, fue Marisol Melesio Nolasco, hija de Margarita Nolasco, reconocida antropóloga en México. En 1976, Marisol ingresa al programa de licenciatura y de inmediato al graduarse se incorporó como profesora.

En cuanto a las preocupaciones por los estudiantes, y con 7 profesores en propiedad (Bonilla, 1994), se creó en 1970 una comisión para estudiar "Posibilidades de trabajo para los graduados de Ciencias del Hombre"; siguiendo el Manual de Clasificación de puestos en la dirección del Servicio Civil, se recomendó incluir los graduados en "asistente de Museo; director de extensión cultural; director de la oficina de población, director de planificación; director general de bienestar, promotor auxiliar de desarrollo de la comunidad; director del instituto Nacional de Aprendizaje, lo que ciertamente fue despejando el panorama relacionado con el empleo de bachilleres.

\section{El contexto sociopolítico, 1945-1970}

Se vivía el sistema bipolar de la posguerra, con Rusia a la cabeza en un lado y Estados Unidos en el otro, la Guerra Fría y el triunfo de la revolución cubana (1959). De acuerdo con Fonseca (1996), ello trajo como consecuencia que militares, empresarios, y sectores medios defendieran el status quo y se opusieran a reformas consideradas comunistas, lo que hizo aumentar los movimientos desafiantes. La economía crece 
aceleradamente entre 1945 y 1970. A partir de 1951, se desarrolló el proyecto del Mercado Común, lo que condujo al crecimiento del comercio interregional, especialmente mayor entre 1960 y 1968 . El conflicto armado entre El Salvador y Honduras en 1969 afectó seriamente al Mercomún, su crisis se agudizó en los setentas. La población creció muy rápidamente, de menos del millón (887 850) en 1950 a casi dos millones (1 916 211) en 1973; se incrementa el número de barriadas en condiciones de pobreza con población proveniente de zonas rurales en busca de empleo, muy limitado, en los centros urbanos, aumentándose así las desigualdades sociales. En los 60, se sentaron las bases de la Teología de la Liberación, se estudió al brasileño Paulo Freire y se escuchó al padre Camilo Torres, sociólogo colombiano, que gran impacto tendrían entre las juventudes universitarias.

\section{Encuentros académicos}

1946 "Primera Conferencia Internacional de Arqueólogos del Caribe”, en Tegucigalpa, Honduras. Jorge Lines fue el delegado por la Universidad de Costa Rica (Bolaños y Carvajal, 2006) .

1958 "XXXIII Congreso Internacional de Americanistas" en San José, Costa Rica. La Presidenta del Congreso fue la Dra. Doris Zemurray de Stone. Jorge Lines formó parte del profesorado de la Universidad de Costa Rica en el evento, al que asistieron los funcionarios del Museo Nacional y de instituciones gubernamentales. En este congreso participaron connotados antropólogos de toda la América y de varios países europeos.

1956 Se celebró en la ciudad de Guatemala el Seminario de Integración Social Guatemalteca, dirigido por científicos sociales norteamericanos e intelectuales guatemaltecos, entre ellos: David Vela, quien residió en Costa Rica y sus contribuciones aparecen en el Anuario de Estudios Centroamericanos; Jorge Luis Arriola quien fue embajador de su país en Costa Rica y cooperó con conferencias en el curso de Antropologia General y el de Antropología Cultural en 1960, y Joaquín Noval, cuyo libro Temas fundamentales de Antropología (1972) se utilizó en C.R. . Este Seminario tiene importancia para la Antropología en Costa Rica porque sus publicaciones fueron leídas en los primeros cursos.

1959 “IV Congreso Indigenista Interamericano". Guatemala. Entre los antropólogos asistentes, estuvo Doris Z. Stone, delegada por Costa Rica.

1964, 1966, 1967 y 1968 "Encuentros centroamericanos sobre enseñanza de la Antropología”. Costa Rica fue una de las sedes. Las conferencias fueron organizadas por el Consejo Superior Universitario Centroamericano, CSUCA, e incluían a los profesores centroamericanos de cursos introductorios de Antropología y Sociología, con el propósito de adoptar lineamientos básicos para la enseñanza de la Antropología en los países del Istmo. Entre los conferencistas, participaron profesores de Francia, Estados Unidos y México. 


\section{Obras representativas o influyentes}

En 1953 se publicó el estudio de Carlos Aguilar Retes, un depósito arqueológico de las faldas del Irazú, estudio novedoso por la preservación de objetos de madera y otros perecederos, debida esta preservación al suelo con materiales volcánicos. Carlos Meléndez Chaverri publicó en 1957, Legislación Indigenista de Costa Rica. Recoge toda la legislación históricamente emitida en el país hasta la fecha de publicación de esta obra. En Etnohistoria; en 1960, Anne Chapman, estadounidense que estudió en su país y en México, y trabajó en Francia hasta su fallecimiento, publicó su tesis en español, la cual había sido presentada a la Universidad de Columbia, en Nueva York. La editó la Universidad de Costa Rica, con el título Los nicarao y los chorotega según las fuentes históricas. Doris Zemurray de Stone, norteamericana, de prolongada residencia en Costa Rica y primera presidenta de la Junta Administrativa del Museo Nacional, publicó La tribus talamanqueñas de Costa Rica (1961). Es una obra imprescindible para quienes desean conocer sobre el devenir de los bribris y cabécares, y se ha reimpreso varias veces. En 1965, Carlos Aguilar publicó la primera edición de Religión y magia entre los indios de Costa Rica de origen sureño. Hubo dos reimpresiones posteriormente, lo que indica demanda de esta obra.

\section{Confrontación y diversificación en la disciplina}

La lucha étnica y campesina; violencia doméstica y de género; el deterioro ambiental y el fracaso de las políticas de modernización e integración de las sociedades rurales: 1970-1985.

\section{Características generales}

Entre las fechas de acontecimientos de interés para caracterizar el periodo se encuentran:

1971 Se creó el Ministerio de Cultura, Juventud y Deportes (5 de julio)- Ley № 4788; 1971 El Museo Nacional pasó del Ministerio de Educación al de Cultura, Juventud y Deportes.

1972 La Asociación de Estudiantes de Antropología llevó a cabo su primer congreso.

1973 Tercer Congreso Universitario (1971-1972, preparación del Congreso). Creación de la Facultad de Ciencias Sociales.

1975 Modificación de los cursos del Plan de Estudios y establecimiento de la Licenciatura en Antropología. Arqueología se formaliza como Sección. Primer volumen de Revista Vínculos en el Museo Nacional; 


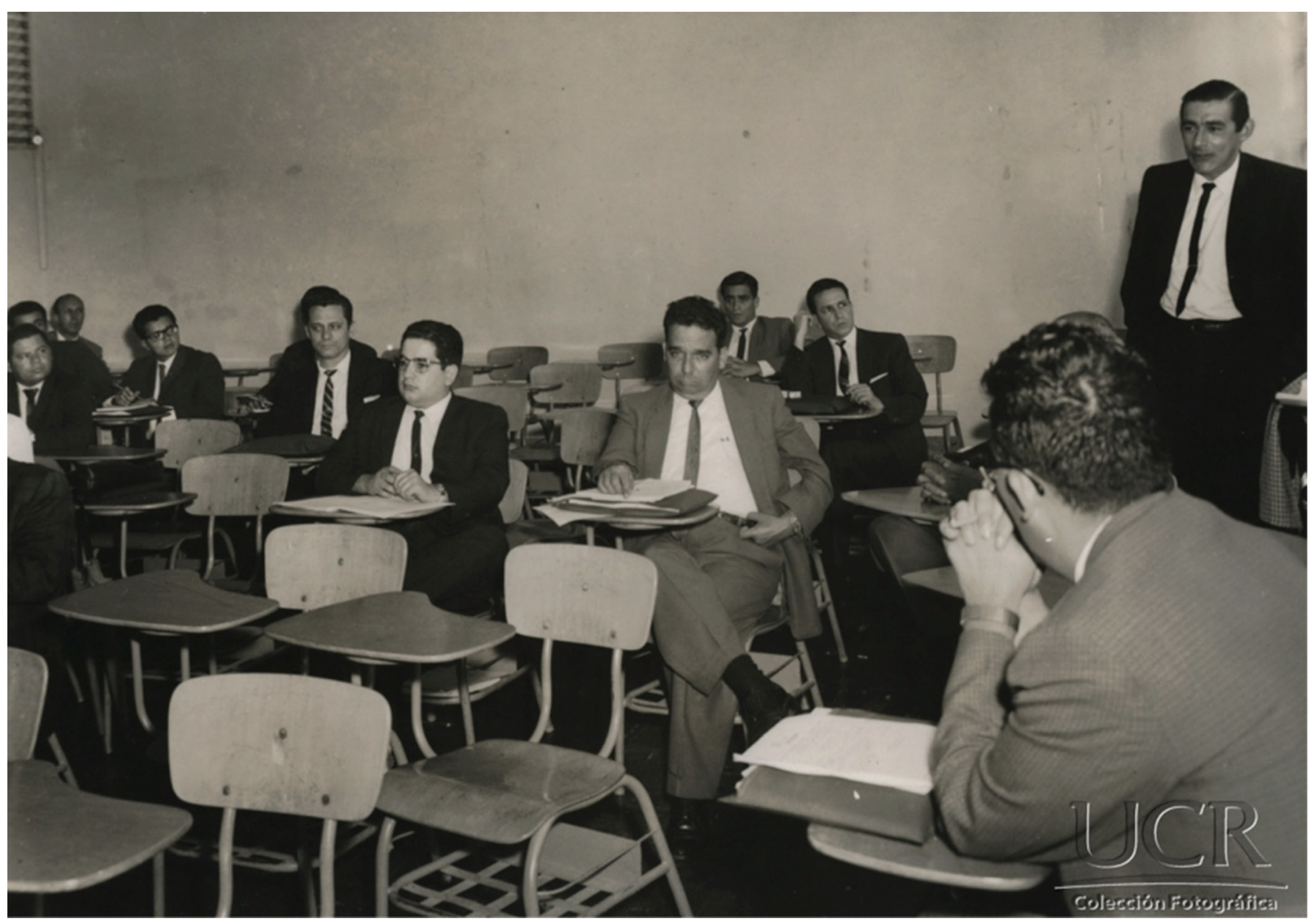

De pie: Fonseca Tortós Eugenio. s/f. Colección fotográfica, Universidad de Costa Rica, Foto N0625. 


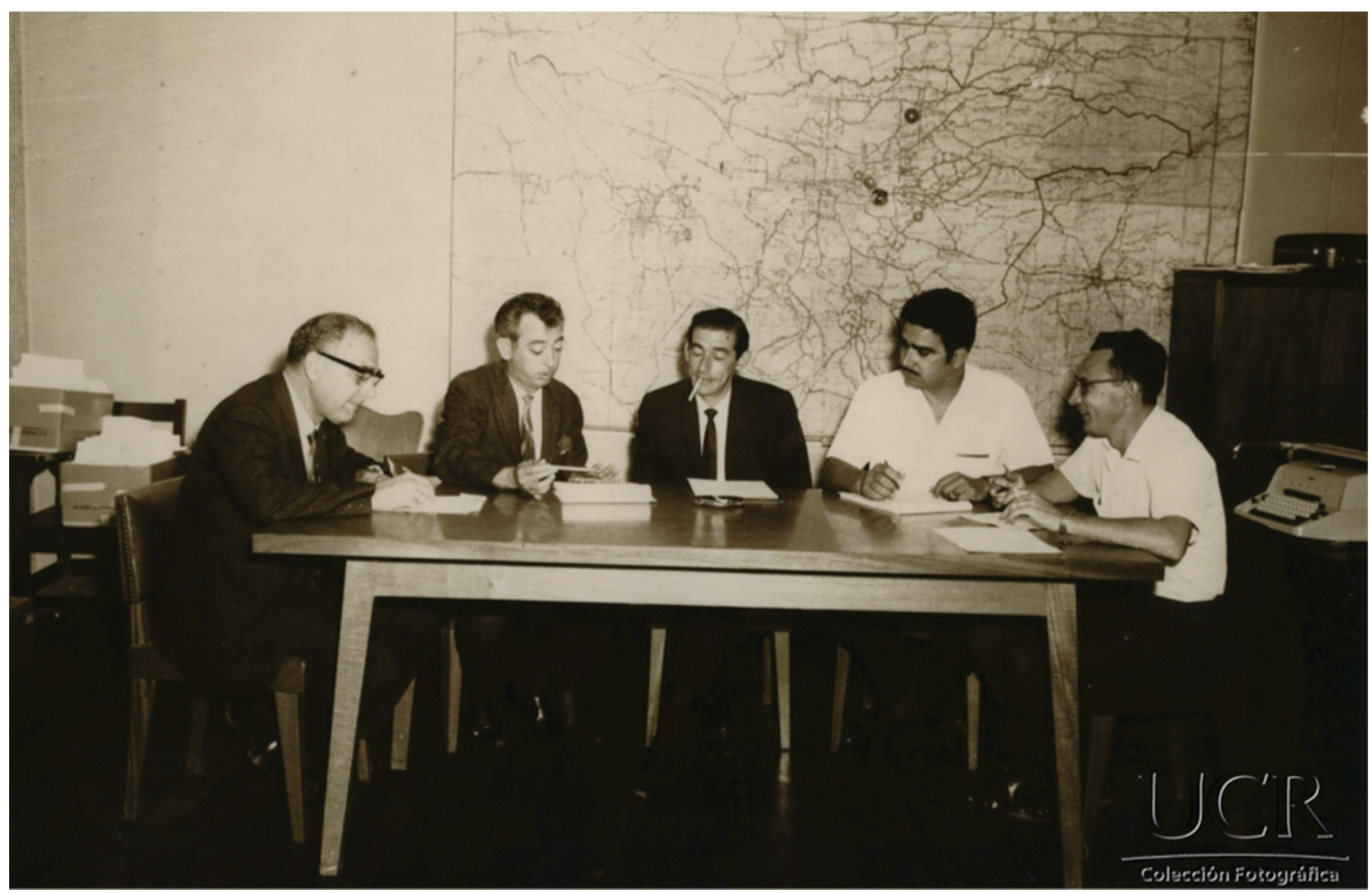

Izquierda a derecha: ?; Adis Gonzalo, Psicólogo; Fonseca Tortós Eugenio; ? ; Pierre Thomas C. s/f. Colección fotográfica, Universidad de Costa Rica, Foto $\mathrm{N}^{\circ} 0639$ 


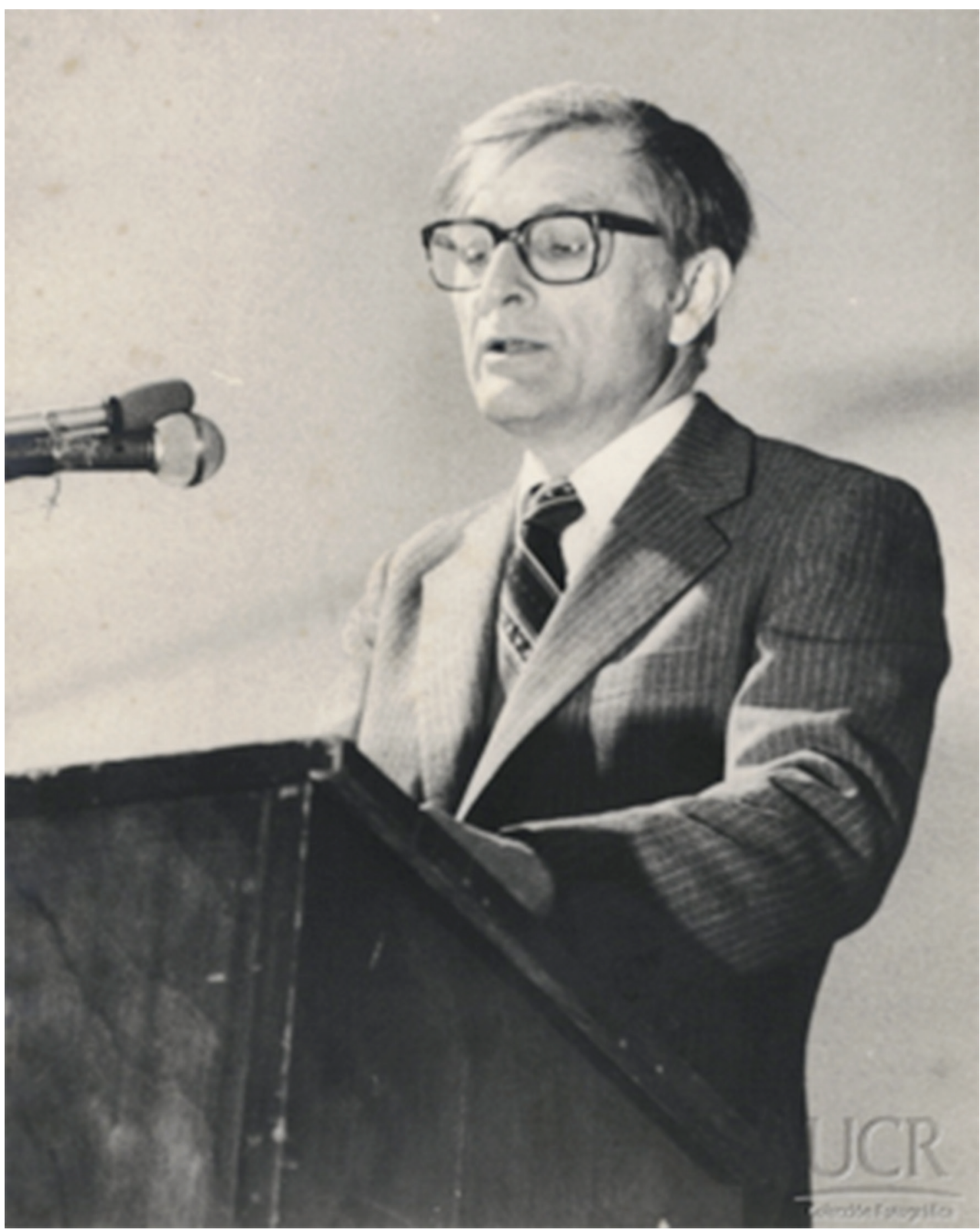

Doctor Gutiérrez Carranza Claudio, Rector. S.f. Colección fotográfica, Universidad de Costa Rica, Foto N 1926. 


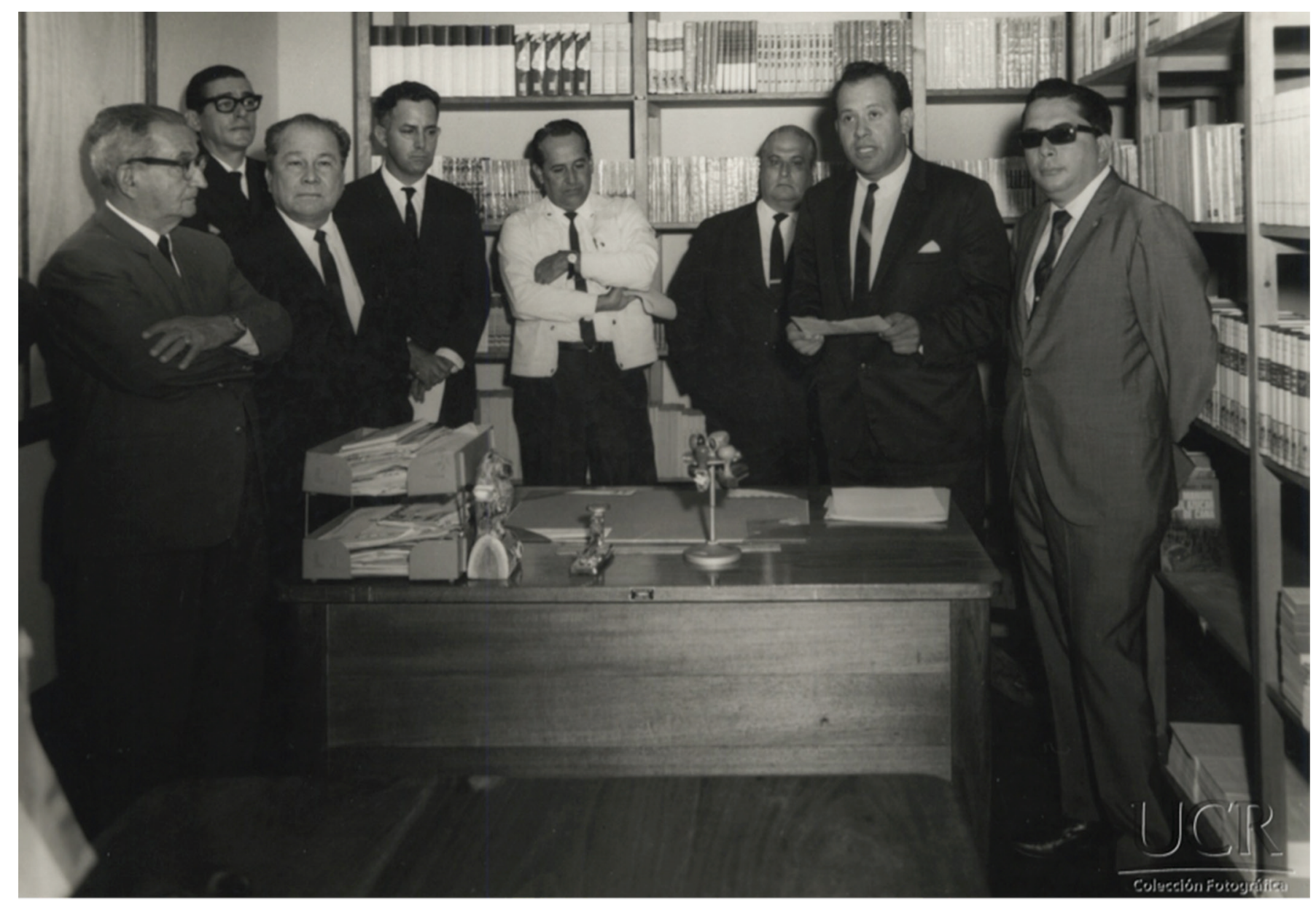

Izquierda a derecha: Padilla Guillermo; Profesor Monge Alfaro Carlos(atrás); Fonseca Tortos Eugenio; Doctor Miranda Mario; Ingeniero Padilla Jorge Emilio; Quirós Santos; Gutiérrez Rodrigo; Chávez Oscar, s.f. Colección fotográfica, Universidad de Costa Rica, Foto N²031. 


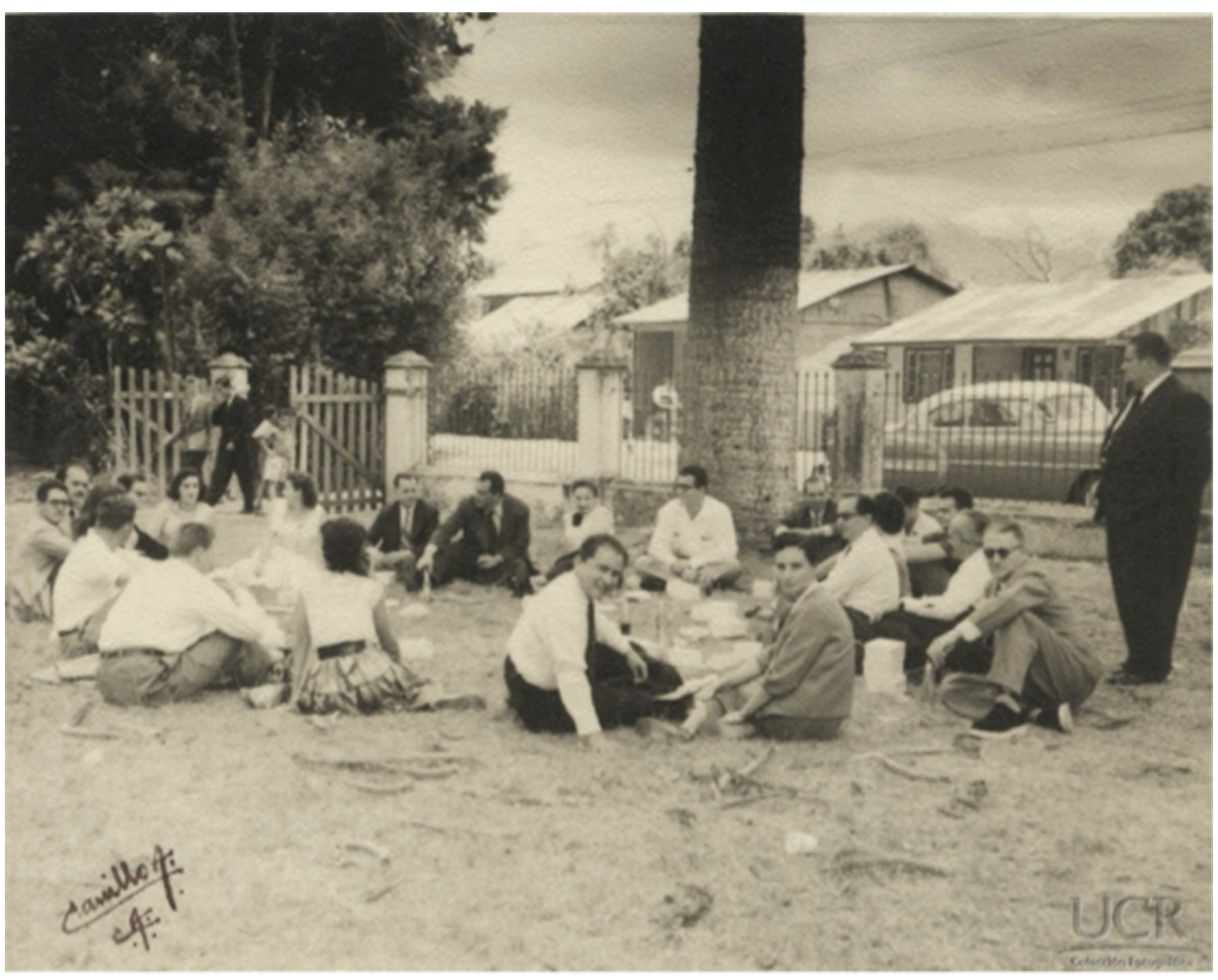

Autoridades universitarias comparten con los nuevos estudiantes el almuerzo. Derecha a izquierda de pie: Santos Quirós; Lines Jorge; Bolaños Hernán; Molina de Lines María; detrás Licenciado Facio Brenes Rodrigo; Profesor Monge Alfaro Carlos; atrás estudiantes, s.f. Colección fotográfica, Universidad de Costa Rica, Foto N²095 


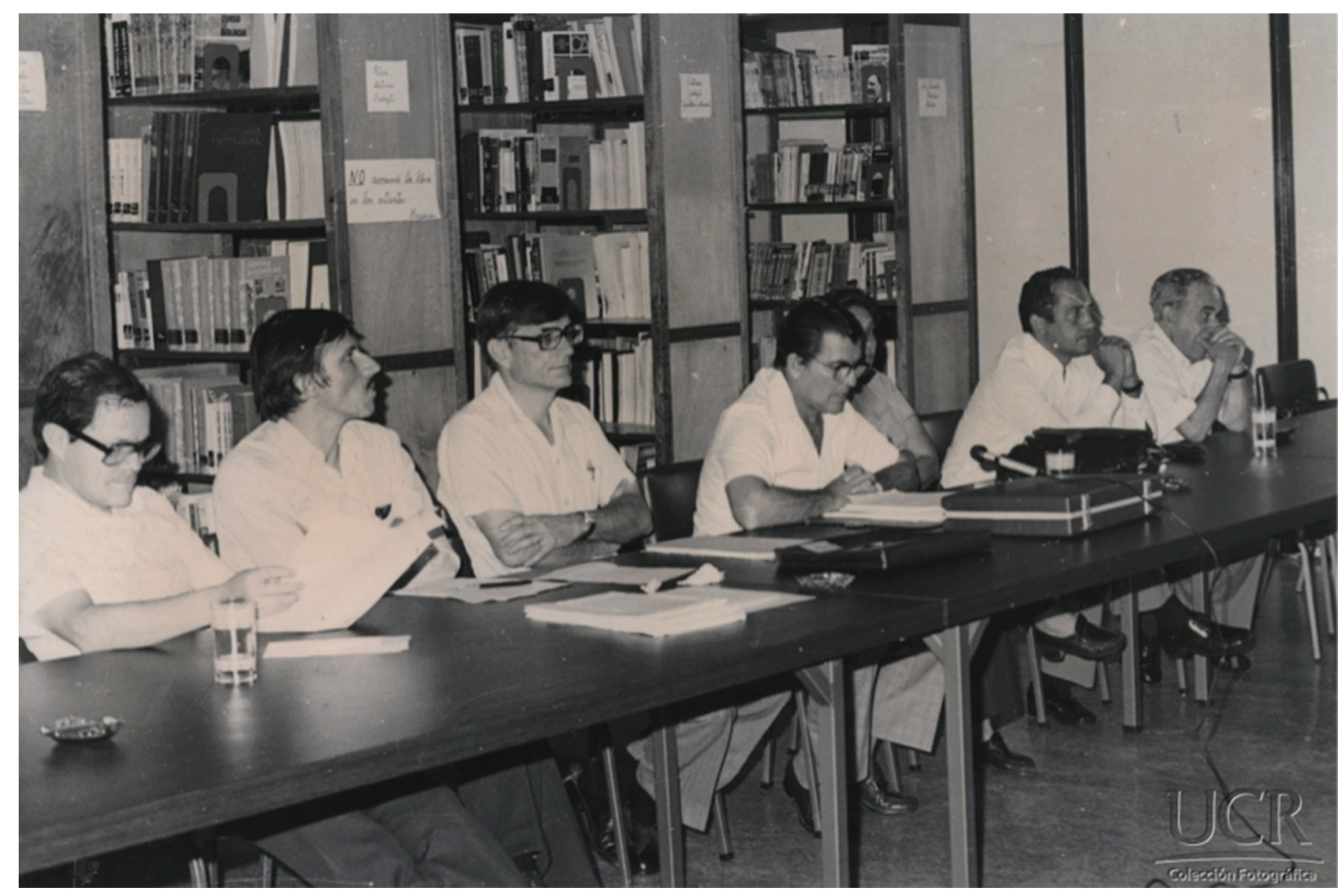

Izquierda a derecha: Doctor Vargas Federico; Arias Luis Fernando; Doctor Gutiérrez Carranza Claudio; Sáenz Alberto; Licenciado Hernández Jaén Mireya; Guevara Herberth; Chaverri Adrián. Visita al Centro Universitario del Atlántico, s.f. Colección fotográfica, Universidad de Costa Rica, Foto N`2130 


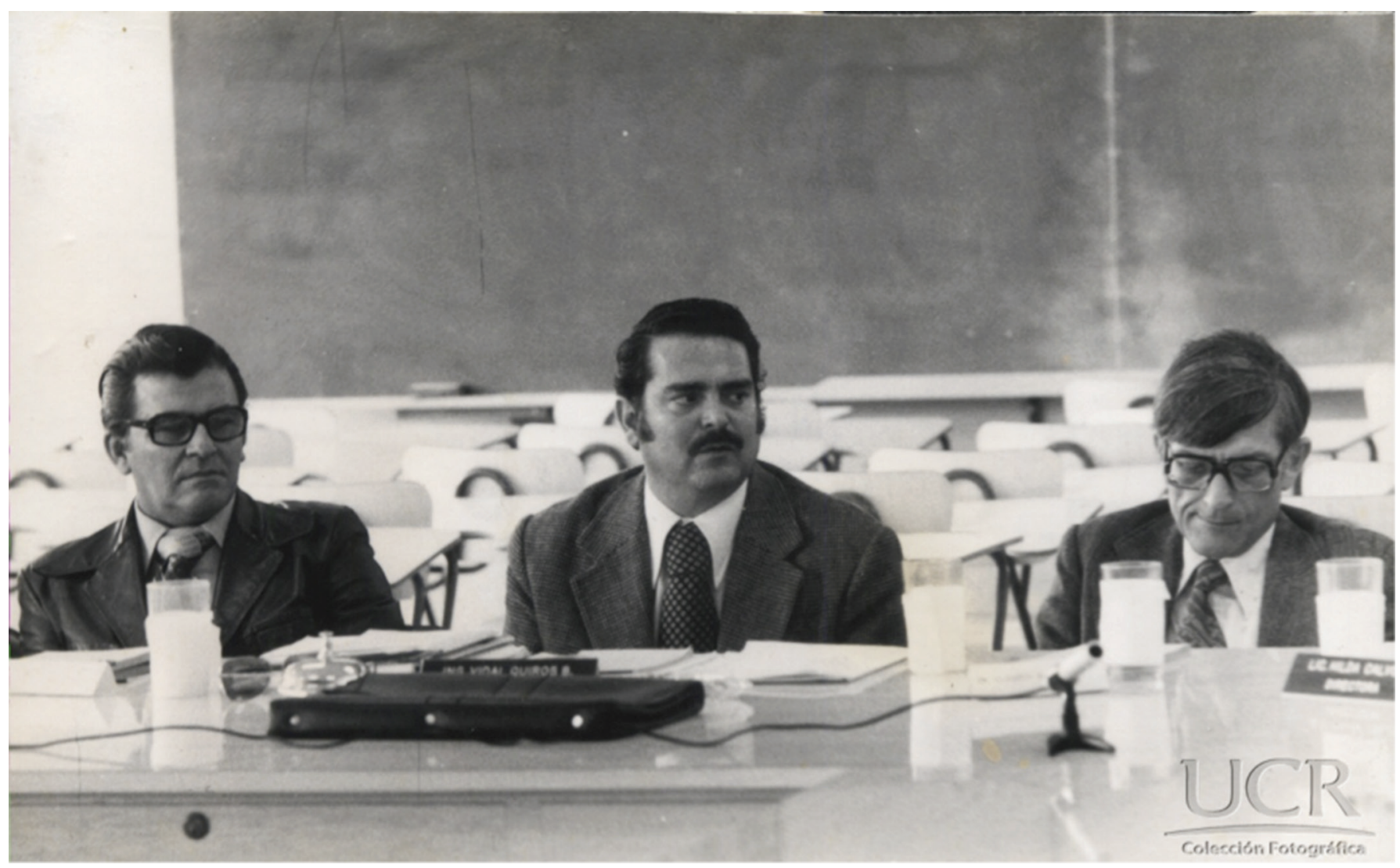

Izquierda a derecha: Sáenz José Alberto Director del Consejo Universitario; ¿?; Doctor Gutiérrez Carranza, Claudio. S.f. Colección fotográfica, Universidad de Costa Rica, Foto N²137 


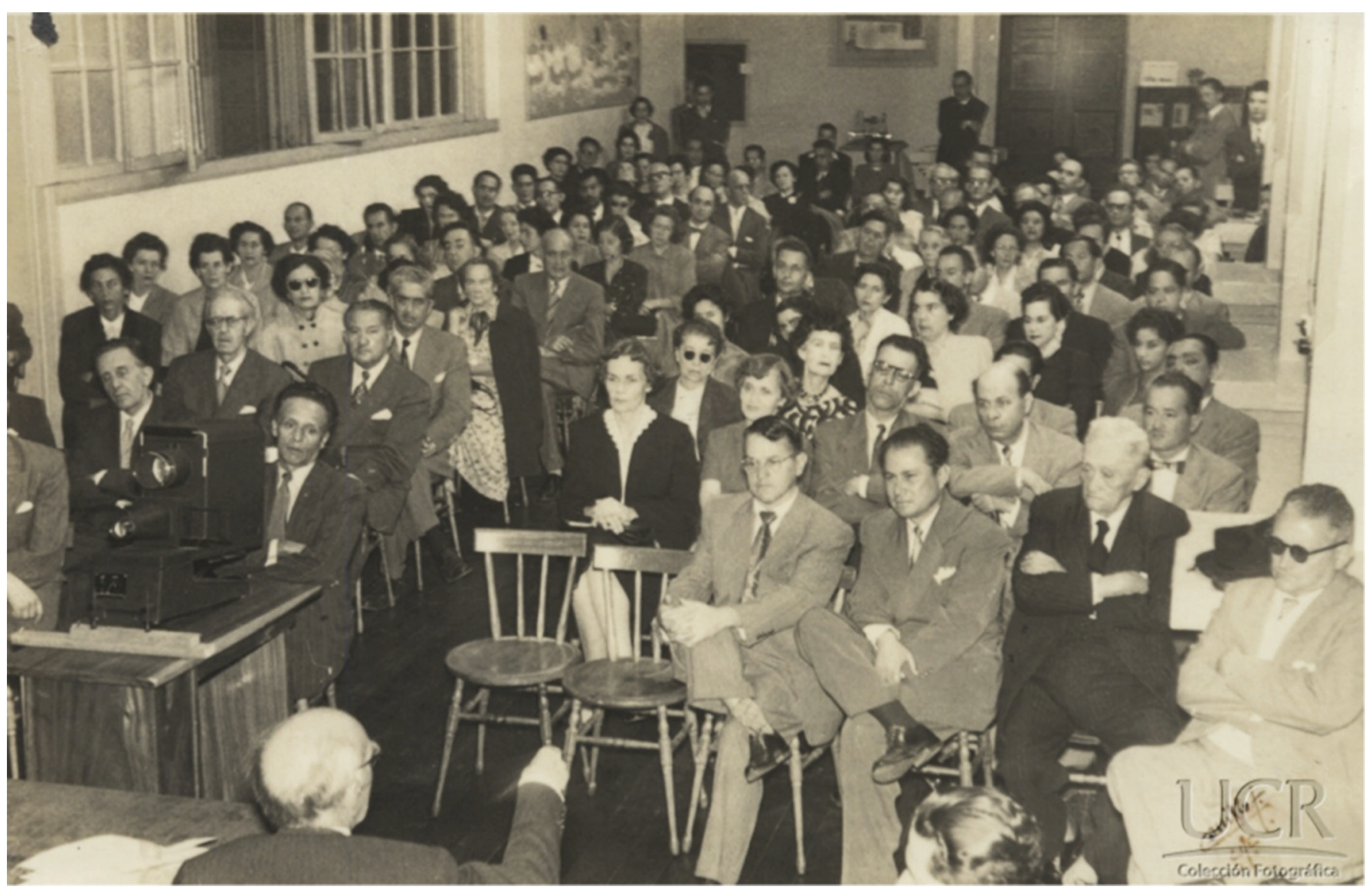

Derecha a izquierda: Primera fila: Lines, Jorge; ?; Profesor Monge Alfaro, Carlos; segunda fila: Bonilla, Abelardo; ?; Orozco, Elsa s/f. Colección fotográfica, Universidad de Costa Rica, Foto N²161 
1976 El Museo Nacional inicia proyecto de investigación en la provincia de Guanacaste. El Departamento de Salud Mental, coordinado por la psiquiatra Socorro Rodríguez, contó en adelante con participación de antropólogas (Giselle Chang (1976-1978); Marlen Castro (1977-1983).

1977 Creación de la Escuela de Antropología y Sociología. Departamento de Antropología dividido en dos Secciones, Antropología Social y Arqueología. Carreras: Bachilleratos con énfasis en Antropología Social o en Arqueología; Licenciaturas con énfasis en Antropología Social o en Arqueología. Primera Licenciada en Antropología Social. La Sección de Estudios de las Tradiciones Populares, del Departamento de Patrimonio Histórico del Ministerio de Cultura, inicia proyecto de investigación en Barba de Heredia. Se inauguró el Museo del Jade Marco Fidel Tristán Instituto Nacional de Seguros. Inició labores el Museo Regional de San Ramón (Se destaca labor de MSc. Flory Otárola Durán en ese Museo.

1978 Modificación del Plan de Estudios para ampliar la temática de la realidad latinoamericana. Integración del Departamento de Antropología en el Ministerio de Cultura. Creación del Departamento de Antropología bajo la dirección de la Lic. Eugenia López Casas, en Inciensa.

1978 Donación de la Fundación Ford al Departamento de Antropología, para profesores visitantes y proyectos.

1979 La Sección de Estudios de las Tradiciones Populares, del Departamento de Patrimonio Histórico del Ministerio de Cultura, convertida en Departamento de Antropología (con apoyo de OEA, Washington, y de INIDEF (Venezuela), inicia proyecto "Investigación, difusión, y promoción de las diferentes manifestaciones culturales de la provincia de Limón.

1980 Se crea el Laboratorio de Etnología. En Inciensa empieza una investigación coordinada por la Universidad de las Naciones Unidas, con el objeto de investigar el papel de la mujer en la tecnología postcosecha en la comunidad de Cot de Cartago. Ministerio de Salud (Educación para la Salud) contó a partir de este año con la colaboración de Xinia Bolaños y de Francis Mata.

1982 La mayoría de los profesores en propiedad tenían sus proyectos de investigación inscritos en la Vicerrectoría de Investigación. Ley 6703 sobre Protección y Conservación del Patrimonio Cultural Arqueológico de Costa Rica, la cual crea el Departamento de Registro Público del Patrimonio Arqueológico y la Comisión Arqueológica Nacional. Primer licenciado en Arqueología.

1983 Inicio de los Cuadernos de Antropología, publicación periódica. (Se han editado 24 números, el último en dos volúmenes, en 2014).

1983 Primer Seminario Taller sobre Antropología y Salud, Laboratorio de Etnología. En Inciensa el Departamento de Antropología pasa a formar parte de una unidad interdisciplinaria llamada Ecología de la Salud. En Incap (con fondos de Universidad de Naciones Unidas, Unicef e Inciensa, proyecto de investigación regional sobre el comportamiento de la familia en torno a la salud-enfermedad.

1985 El Departamento de Antropología e Historia del Museo Nacional en investigaciones regionales arqueológicas (Gran Nicoya Juan Vicente Guerrero, Área Metropolitana Myrna Rojas, Aguacaliente de Cartago Wilson Valerio, Vertiente Atlántica Maritza Gutiérrez, Pacífico Central Francisco Corrales, Térraba-Coto Brus Roberto Drolet. 
Aumentó en este período 1970-1985, el abordaje de procesos de transculturación entre los indígenas, la modernización de sus comunidades y las de las comunidades campesinas tradicionales; el Estado tomó parte activa en proyectos de modernización del agro y en promoción de la industria en zonas urbanas. Costa Rica se articuló con Centroamérica mediante la carretera interamericana ampliando así sus esferas de interacción económica, política y cultural. La expansión agrícola encontró su límite y las luchas campesinas por la tierra mezclaban el ajuste a la modernidad con la supervivencia diaria de las comunidades rurales. E1 Caribe, con sus plantaciones de banano, se integra más explícitamente a los planes nacionales de desarrollo.

El profesorado del Departamento de Antropología era diverso en este período. Se emplearon profesores cuya preparación en la disciplina fue en Europa, Norteamérica o Sudamérica: Entre ellos, en Antropología Biológica trabajaban el Dr. Ronald Chaves, graduado en Italia; en Antropología Social, Claudine Van Gyseghem, graduada en Bélgica; Josefina Piana, graduada en Argentina, Marta Eugenia Pardo, graduada en Louisiana, EE.UU; entre los primeros graduados, continuaron estudios en Europa y luego habían sido contratados como profesores, William Reuben (Holanda), José Antonio Camacho (Inglaterra y Francia), Olga Echeverría (Francia); y Ana Isabel Porras (Inglaterra y Argentina). En cuanto a personal de Norteamérica, la modalidad fue de participaciones cortas en cursos o de investigaciones de campo conjuntas, aunque en Arqueología hubo más permanencia. Tal como lo reporta Ibarra Rojas (2010), fue a finales de los años 70 y durante los 80, que los arqueólogos Michael J. Snarskis, Federick K. Lange, Robert Drolet, norteamericano, y Luis Hurtado de Mendoza (peruano, con doctorado norteamericano), complementaron la labor de Carlos Aguilar Piedra en el entrenamiento de estudiantes.

Las primeras tesis de licenciatura en Antropología Social se producen en este período. Las graduadas y graduados fueron: 1977, Eugenia López Casas; 1979, Giselle Chang Vargas y Marlene Castro Odio, María Soledad Melesio Nolasco, Margarita Bolaños Arquín y Nancy Cartín Leiva, Patricia Montenegro Gurrero; 1980, Nora María Solano Quesada, Álvaro Dobles Ulloa; 1981, María Eugenia Murillo Madrigal y Mayra Cartín Brenes; 1982, Carlos Camacho Nassar; 1983, Joaquín Gil Q; 1984, Enrique Hernández Camacho, Eugenia Ibarra Rojas, Blanca Arce López y Hannia Silesky Jiménez; 1985, María Josefina Carlos Cabrera, Enid Mayela Pérez Castillo y Mayra Zapparoli Zecca. En Arqueología tenemos tres licenciados en el período: Ricardo Vázquez Leiva en 1982; Ana Cecilia Arias y Sergio Chaves en 1985.

La confrontación y diversificación teóricas se basaron en los siguientes elementos: (1) Existía el interés de hacer una Antropología propia, a distancia de la norteamericana y en cierta medida de la escuela indigenista mexicana. Sin embargo, ambas tradiciones continuaban teniendo importancia, tanto porque había profesionales con estudios en una y en otra, como porque las relaciones académicas con la Antropología de México y de EE. UU, no solo no cesaron, sino que se hacían cada vez más frecuentes. (2) La violencia política en Centroamérica en las décadas de los años 1970 y 1980, daba lugar a debatir sobre el papel del antropólogo o antropóloga. Nicaragua, sede de la Revolución Sandinista (1978-1979), fue uno de los ambientes para 
revisar teorías del desarrollo. Se trató la autonomía étnica; los abordajes de lo nacional, de lo regional, del papel de las clases obrera y campesina, la consolidación del movimiento urbano, el papel del Estado y de las mujeres. Para Bolaños (2001a):

Los inicios de la década de los setenta fueron políticamente muy convulsionados en toda la región centroamericana. Es un período en que se destacan los movimientos estudiantiles inspirados en un ideario anti-imperialista fundamentalmente antinorteamericano y profundamente latinoamericano.

(3) Con el amparo y los recursos del CSUCA, con sede en Costa Rica, hubo oportunidad de conocer las inquietudes de intelectuales de prestigio de Centroamérica sobre diversas perspectivas y tradiciones disciplinarias. Elementos como los anteriores hacían razonable la búsqueda de la "Antropología propia". (4) Por otra parte, el decenio 1980- 1989 fue mucho más complejo y diverso, lo que condujo, en la investigación y en la docencia, a enfatizar en especialidades tales como Antropología rural, Etnohistoria, Antropología de la Educación, y otras, sin contar las que se promovieron por el trabajo de graduados y graduadas en las instituciones públicas, como Antropología y Salud, Antropología y Patrimonio Cultural, Antropología y Desarrollo, etc. Por la parte de la Arqueología, se debatían el modelo procesal culturalista, los abordajes de la Ecología Cultural y el enfoque marxista de la Arqueología Social. (5) En el contexto socioeconómico hubo otra fuente para confrontar o para diferir: En Centroamérica se realizaban esfuerzos para mantener la integración económica, estimulando la industrialización mediante la substitución de importaciones, y tratando de ajustar el mercado común a las realidades de los países. La década de 1970 se caracterizó por la crisis de la integración: Los precios de los productos de exportación declinaron, los de las importaciones aumentaron; contribuyeron a la crisis catástrofes naturales en el istmo. Ello generó conflictos sociales desde el final de esa década y durante los años ochenta. En las apreciaciones de varios sociólogos, la integración era "desarrollista" por su énfasis en lo técnico y económico, la industria no superaba la base agraria de latifundios, sus insumos eran extranjeros, no solo se agudizó la dependencia económica, sino la política. Un efecto fue la constante migración del campo a la ciudad, con el aumento de personas en los cinturones de miseria urbanos. En las décadas 1970 y 1980 , sobresale el énfasis en actividades gubernamentales relacionadas con los planes de desarrollo regional y desarrollo nacional, pero el país se ve afectado por la crisis económica.

En cuanto a la continuidad de la influencia mexicana, en 1973, bajo la dirección y enseñanza del Dr. Alejandro D. Marroquín, hubo un seminario en Costa Rica, con carácter centroamericano. El seminario trató temas de muy diversa índole como: antropología aplicada, indigenismo, métodos y técnicas de investigación social, problemas sobre reforma agraria, educación de adultos, desarrollo de la comunidad en el desarrollo nacional, relaciones humanas, y otros (Instituto Indigenista Interamericano, 1973). También la revista América Indígena dedicó un número a Costa Rica en 1974, y otro en 1983. La producción mexicana de artículos y libros era conocida y utilizada, como aún sucede al presente. En 1972, se inicia una reforma del Plan de Estudios con acercamiento a la perspectiva sociológica, en ese entonces muy dedicada a los 
teóricos de la dependencia para explicar el subdesarrollo. Esto se atribuye (Bolaños, 1993) a influencia del movimiento estudiantil mexicano de 1968 y a una proclama que los estudiantes de la ENAH, emitieron en los años de 1970. Se llevó a cabo el "I Congreso de Estudiantes de Antropología", de la Universidad de Costa Rica, en agosto, 1972. Además, en el año 1978 por iniciativa, desde México, de la antropóloga Larissa Lomnitz, y desde Costa Rica, de José Antonio Camacho, director del Departamento de Antropología, se acuerda un programa de intercambio académico entre la Fundación Ford y el Departamento. Entre 1980 y 1981, el Departamento de Antropología, a cargo de Margarita Bolaños, recibe como profesores invitados a Andrés Fábregas, Héctor Díaz Polanco, Jaime Litvak, Ernesto Vargas y Rosa María Vargas. Por otra parte, los estudios rurales dominaron las preocupaciones de la antropología costarricense y a ello contribuyeron notablemente los trabajos de los mexicanos Guillermo Bonfil Batalla, Luisa Paré, Arturo Warman, Héctor Díaz Polanco, Andrés Fábregas, Margarita Nolasco, Gonzalo Aguirre Beltrán, entre otros.

En el decenio 1980-1989, varias razones pueden justificar un mayor acercamiento a la antropología mexicana. Se contaba en Antropología Social con Eugenia López Casas (mexicana, primera licenciada en Antropología de la UCR, luego doctorada en Inglaterra), Nancy Cartín, egresada de la maestría en Antropología Social de la Universidad Iberoamericana, Oscar Fonseca, quien, aunque con Maestría en Arqueología obtenida en la Universidad de Pittsburgh en 1977, había hecho antes una pasantía en México.

Investigaciones realizadas en el período se recogieron en la Revista de Ciencias Sociales de los años 1984(1), 1985(2), y 1987(3), por gestión del Laboratorio de Etnología, creado en 1980 por esfuerzos importantes de José Antonio Camacho Zamora y Marta Eugenia Pardo Angulo, e inaugurado en 1981, había iniciado sus esfuerzos en publicaciones por gestión de Nancy Cartín Leiva. También representan el período, las investigaciones en el marco de la Antropología de la educación que se hicieron adscritas al Instituto para el Mejoramiento de la Educación Costarricense (I.I.M.E.C), en el Proyecto de Epistemología Genética y Educación, de 1983 a 1886, con extensiones posteriores; en ese proyecto interdisciplinario se hicieron varios seminarios y salieron varios artículos. Trabajaron en el proyecto, con la psicóloga Dra. Zayra Méndez y otras personas, José Antonio Camacho y Olga Echeverría.

\section{El contexto sociopolítico: 1970-1985}

Marco Antonio Herrera M. afirma:

La propuesta social-demócrata de los años 70 contó con la participación de antropólogos y el estado costarricense les brindó en cierta forma un espacio, pero transitorio". Agrega que las dependencias en que trabajaron no fueron permanentes. Un caso es el de la Oficina de Información de la Casa Presidencial, creada en 1974, en la cual participaron Ana Mercedes Brealey, José A. Camacho, Carlos Camacho Nassar, entre otros (Herrera, 1993, p. 82). 
Herrera (1993) detalla el empleo de antropólogos en las instituciones públicas y los datos pertinentes sobre estas instituciones, los problemas y crisis del país en estos años, como cuando en 1978 se empieza a gestar una crisis como la sufrida en los años 30.

\section{Encuentros académicos}

1973 “Seminario de Centroamérica y Panamá sobre Indigenismo y Antropología Social”. En CEDAL, La Catalina, Heredia, Costa Rica. Participaron como profesores el Dr. Gonzalo Rubio Orbe, Director del Instituto Indigenista Interamericano, el Dr. Alejandro Dagoberto Marroquín, jefe de la Sección de Investigaciones Antropológicas del Instituto, y el profesor Víctor Montoya, boliviano de la OEA destacado en el Salvador. El Seminario trató los avances metodológicos de la Antropología Social y de otras ciencias sociales abocadas a resolver el denominado "problema social del indio" y de los grupos marginados de Hispanoamérica, en especial la región istmeña. Se abordaron temas como la educación de adultos, los métodos y técnicas de la investigación social, y el trabajo comunitario. Especialmente se abordó la lingüística aplicada en el campo indígena en todo el Istmo (Anuario, 1974[1]).

1974 “Seminario sobre Indigenismo y Antropología Social”. En CEDAL, La Catalina, Heredia, Costa Rica, se reunieron 30 antropólogos y antropólogas de América bajo los auspicios del Instituto Indigenista Interamericano, la Fundación Friedrich Ebert, Cedal, OEA, IICA y otras entidades, lo cual resultó en un documento para mejorar la atención del indígena en el continente (Anuario [2]).

1974 "Seminario sobre la enseñanza de las Ciencias Sociales”, organizado por la Facultad de Ciencias Sociales de la Universidad de Costa Rica, en Cedal, con la participación de expertos de Centroamérica, Panamá y México. Tuvo el patrocinio de CSUCA y de la Fundación Friedrich Ebert (Anuario [2]).

1975 "Primer Congreso de Antropología y de la Defensa del Patrimonio Cultural de la América Central", en Cedal y en la Universidad de Costa Rica. "Una reseña de este fructífero congreso aparece en el Anuario (2). En la subcomisión de investigación estuvieron: Dr. Claude Baudez, Dr. Frederick Lange, Maestro Carlos Aguilar Piedra, Dr. Michael Snarskis, Dr. Víctor Manuel Arroyo, Dr. Hugo Fernández, Prof. Luis Ferrero, Lic. William Reuben. La subcomisión de Defensa del Patrimonio incluyó al Dr. Daniel Rubín de la Borbolla, quien envió una ponencia para ser leída en el Congreso. Los participantes, en las sesiones realizadas en el Laboratorio de Arqueología en la Universidad de Costa Rica, fueron: Gloria Hernández (E1 Salvador), C. Baudez (Francia), Wolfgang Haberland (Alemania), Richard Magnus (EE.UU), María Teresa Montealegre de Osorio (Nicaragua) Jeanne Sweeney (EE.UU.), Carlos Aguilar Piedra (C.R.), William S. Kennedy (EE.UU.) Michael J. Snarskis (Costa Rica), Richard Cooke y Olga Linares (Panamá). Como observadores: Elizabeth Easby (EE.UU.); Roberto de la Guardia (Panamá); Jorge Espinoza (Nicaragua); María Bozzoli, Luis Ferrero y Héctor Gamboa (C.R.). En las sesiones de Patrimonio, en Cedal, estuvieron presentes delegados de todos los países de Centroamérica y sus ponencias aparecen en la Memoria del Congreso.

1981 "El sureste de Costa Rica como región de desarrollo". San Isidro del General. Varias entidades organizadoras, asistió un buen número de antropólogos y antropólogas. 
1983 “Cot: Historia y tradición”, foro del proyecto de Investigación-Acción de la Prof. Margarita Bolaños.

1983 “Simposio Arqueológico El cantón de Turrialba y la Identidad Nacional”. Con participación de profesores del Departamento. Turrialba.

1984 “Primer Simposio Científico sobre Pueblos Indígenas Costarricenses”. El Depto. de Antropología coadyuvó en la organización, la participación fue interdisciplinaria.

1984 "Primer Simposio sobre investigaciones en la región brunca. Marzo. Golfito

Interdisciplinario, con participación de antropólogos y antropólogas.

1985 “Primer Seminario-Taller sobre Antropología y Salud”. Laboratorio de Etnología.

1985 "Primer Congreso Nacional de Antropología”. En este último se presentaron 43 ponencias, de las cuales 32 correspondieron a profesionales graduados de la Universidad de Costa Rica

1981 "Etnodesarrollo y Etnocidio en América Latina". Cedal, convocado por la Facultad Latinoamericana de Ciencias Sociales, Flacso. Hubo una buena representación de antropólogos costarricenses. Delegados de diversos países. En la delegación mexicana, participaron Jorge Díaz Olivares (Chiapas), Leonel Durán Solís (Culturas Populares de la Secretaría de Estudios Populares, SEP), Salomón Nahmad Sitton, Nemesio Rodríguez, Guillermo Bonfil Batalla y Stefano Varese.

1983-1987 "Estado y Desarrollo de la Costa Atlántica de Centroamérica”, patrocinado por el CSUCA. (CSUCA, 1988). Dos de los encuentros de este proyecto centroamericano fueron en San José (1983), otro en Limón (1987).

\section{Obras representativas o influyentes}

El Dr. Carlos Meléndez, y el escritor Quince Duncan (1972), recogen en su obra El negro en Costa Rica, varios artículos sobre la población negra caribeña. Entre ellos está un resumen de la tesis presentada en Puerto Rico por Roy Simon Bryce Laporte en 1962, sobre la vida cotidiana en una comunidad afrocaribeña cercana a Limón. Uno de los objetivos del libro fue dar a conocer que Costa Rica era un "país pluriétnico y culturalmente diverso, e incentivar el respeto por las diferencias".

En 1975 apareció el primer volumen de la Revista Vínculos, y en el período sumaron once. Incluye artículos de Arqueología y de las otras ramas de la Antropología. Entre 1982 y 1985, se editaron 5 Cuadernos de Antropología en el Laboratorio de Etnología. Ambas revistas se están publicando periódicamente en el siglo XXI.

Cultura popular tradicional: fundamento de la identidad nacional de Giselle Chang Vargas y Fernando González Vásquez (1981) es un ensayo que presenta algunos lineamientos teóricos acerca del folklore, dirigidos a despertar un mayor interés en la revitalización de la cultura popular tradicional como base de la identidad cultural costarricense, que, de acuerdo con los autores, es desfigurada y mistificada debido a diversas influencias de comercialización y "turistización” de las tradiciones. Su contenido es el siguiente:1) Síntesis sobre la 
Antropología y el concepto de cultura; 2) Origen, significado y usos del concepto de folklore, taxonomía, reseña de estudios folklóricos; 3) Problemática en torno a la identidad cultural: lo popular, lo tradicional, lo geográfico; transculturación y cultura de masas; comercialización y "turistización” de la cultura folklórica.

\section{El contexto de los procesos de la globalización}

Las alternativas populares de desarrollo; las culturas populares, la economía informal, la sostenibilidad de los sistemas tradicionales de producción, el ecoturismo, desarrollo sostenible y nuevas alternativas de poder: $1985-2000$.

\section{Características generales}

Entre las fechas de acontecimientos de interés para caracterizar el periodo se encuentran:

1986 "Encuesta de la Asociación Costarricense de Antropología ACAN".

1986 “Taller del Agro en Costa Rica”, Laboratorio de Etnología.

1986 "Estado y desarrollo de la costa atlántica de Centroamérica”, Proyecto de CSUCA.

1987 Mesa Redonda "La trayectoria de la Antropología en los últimos diez años”. 24 profesores en el Departamento. Diez personas graduadas en Arqueología con Licenciatura.

1988 "Primer Encuentro Centroamericano", en Turrialba.

1991 "Cuarto Taller Centroamericano de Antropología”. Universidad de Costa Rica.

1994 Creación de la "Red Centroamericana de Antropología". Universidades centroamericanas y del sur de México.

1995 Se crea Museo Regional Omar Salazar Obando, Turrialba. Destacable labor en ese Museo de la Directora Lic. Dalia Castillo Campos.

1997 Nuevo plan de estudios para Bachillerato y Licenciatura.

1998 Inicia la Primera promoción de la Maestría en Antropología: marzo 1998.

1999 Segundo Congreso de Antropología y Arqueología, diciembre.

1999 Segundo año de la primera promoción de la Maestría: concluye diciembre 1999.

En este periodo se reflexionó sobre las condiciones de la vida urbana, de las mujeres y de los migrantes; se analizan en las investigaciones y en los cursos. Las primeras promociones de graduados ya no tenían campo en la misma academia necesariamente; debían el creciente número de graduados y graduadas abrirse campo en su sociedad. Al efecto, las organizaciones no gubernamentales, ONG, con financiamiento proveniente de diversos países, cumplieron un papel en absorber estos profesionales, así como lo hicieron las instituciones gubernamentales; algunas ONG tenían orientaciones políticas definidas. Estas, y entidades 
extranjeras, abrieron posibilidades mediante consultorías y asesorías. Las universidades también respondieron a las necesidades comunales, lo que permitió el desarrollo de proyectos de extensión universitaria (Acción Social en la UCR, desde 1975). Se recibió financiamiento extranjero para propiciar desarrollo local, comercio justo, proteger el medio ambiente e incrementar la participación femenina (Bozzoli, 1994).

En 1987, la Dra. Eugenia López, directora del Depto. de Antropología, informó sobre cursos cortos impartidos por los doctores Robert Carmack y Gary Gossen de la Universidad de Nueva York en Albany y el Dr. Euclides Catá Guilarte, director de la Escuela de Sociología de la Habana, Cuba; y sobre conferencias por el Dr. Norman Palma, director de la Escuela de Estudios Internacionales de la Universidad de París, Francia. En el Departamento trabajaban 24 profesores. Este año contó con un número considerable de graduados en arqueología: Juan Vicente Guerrero Miranda, Aida Blanco Vargas, Wilson Valerio Lobo, Maureen Sánchez Pereira, Floria Arrea Siermann, Patricia Fernández Esquivel, Dalia Castillo Campos, Eduardo Castillo Ortiz, Myrna Rojas Garro, Carlos Valldeperas Acosta. En los años siguientes, de 1988 a 2000 se graduaron otras 17 personas en Arqueología. Ellos y las tres personas mencionadas en el periodo anterior (Vázquez, Arias y Chávez) sumarían 30 arqueólogos y arqueólogas de profesionalización nacional entre 1982 y el 2000.

La temáticas tradicionales continúan desarrollándose y surgen algunas nuevas; tales como el interés en la historia de la Antropología o pensamiento antropológico, género, procesos de paz, ecología y desarrollo sostenible, el nuevo entorno urbano, y antropología jurídica (el Dr. Marcos Guevara, con trabajos en este campo, se integró al Departamento en 1986). Mauricio Murillo Herrera (2008) analiza la situación de la Arqueología especialmente desde finales de los años 70 hasta principios del siglo XXI, por lo que abarcó lo acontecido en ese campo en este período.

Además, entre 1989 y 1992, se realizaron los talleres del Plan de Antropología Centroamericana, con el auspicio del CSUCA, en cada país centroamericano, incluida Costa Rica.

Un resultado de la atención al pensamiento antropológico es el énfasis del Primer Encuentro Centroamericano, en Turrialba, en 1988, sobre una aspiración centroamericana por consolidar la disciplina mediante esfuerzos propios en los enfoques organizativos, metodológicos y teóricos. Las tendencias señaladas por Bolaños (2001b) fueron comunes a todos o algunos de nuestros países centroamericanos. El mundo entró en una nueva etapa de globalización.

Los antropólogos costarricenses nos abríamos campo en dos frentes: la sociedad civil (la calle, como dicen algunos colegas) y la academia. Con la reducción del gasto público para aliviar la deuda interna y externa, muchas de las instituciones estatales donde trabajaron los antropólogos, fueron cerradas. Nunca antes el terreno se había mostrado tan propicio para hacer investigación propiamente antropológica, las condiciones estaban para pensar la realidad antropológicamente. Había muchos aspectos de la realidad social que explicar y desde muchos ángulos, donde los antropólogos habíamos acumulado experiencia”. 
Los debates sobre la globalización y sus efectos fueron comunes. Lo rural, la salud, la violencia y la migración, fueron temáticas frecuentes. Los sectores más impactados por la crisis de los ochenta fueron los productores agrícolas en general y los sectores urbanos pobres; esta situación generó proyectos de investigación y de acción. En los estudios rurales coincidían antropólogos con otros profesionales en equipos de trabajo. Se estudiaban estrategias de supervivencia y temas de identidad (véase Bolaños, 2001, 2002). Se hizo un esfuerzo por hacer la investigación participativa desde el planteamiento del problema hasta la elaboración de las preguntas y las técnicas de recolección. Se imparten cursos de Antropología en las cuatro universidades estatales.

Como lo ha expresado Zúñiga Vargas (2001, p. 1): "En el caso de los últimos diez años del veinteavo siglo, el acelerado proceso de globalización nos ha hecho voltear la mirada a lo cotidiano, a las identidades locales, a la forma de pensar y desarrollarse cada uno de los actores de la sociedad dentro de esta gran masa de información". Igualmente sobre el desarrollo de la antropología urbana al finalizar el siglo XX, Margoth Marín (2001, p. xx) expresa: "Las investigaciones urbanas no estuvieron exentas de los cambios sociales que se estaban gestando en todo el planeta, por lo que los estudios antropológicos debían de crear nuevas maneras para abordar los fenómenos sociales que se estaban presentando". Continúa Marín Murillo con ejemplos de cambios en el abordaje de fenómenos sociales, al mencionar cómo Carmen Murillo ejemplificó la transición de lo rural a lo urbano en el plano económico en toda Centroamérica donde cada vez más se alejaban los países de su vocación del café, del banano y de la caña y se acercaban más a los productos de las industrias maquiladoras con sus tecnologías específicas; el texto aludido de Carmen Murillo Chaverri (2000) es el siguiente:

En el plano económico, Centroamérica experimenta importantes virajes en sus economías, que apuestan ahora cada vez más por salidas que las alejan tendencialmente de su anterior vocación histórica ligada a la flor del café, la humedad del bananal, la dulzura de la caña y el brillo del metal, para dar paso al cultivo de nuevos productos, al establecimiento de industrias maquiladoras rudimentarias o con tecnologías 'de punta', a las torres financieras con sus intrincados nexos internacionales, así como también a oleadas crecientes de turistas que, a través del disfrute de su ocio, ponen a trabajar el engranaje de la industria sin chimeneas.

Los cambios económicos como estos estimularon estudios urbanos, los cuales requirieron técnicas y enfoques apropiados para esta sociedad diferente a la rural tradicional. En el ámbito costarricense se conocieron estudios de gente urbana, por ejemplo de Janina Bonilla, Marta Eugenia Pardo, José Antonio Camacho, Marco Herrera, Enrique Hernández, enfocados a salud, educación y cultura en su contexto institucional o a proyectos de vivienda. Marín Murillo también se refiere a una conclusión de Bolaños (1993, p. 62) según la cual, el desarrollo de la Antropología urbana en Costa Rica “... se perfilaba como una alternativa de trabajo, sin embargo, ha perdido su vigor inicial, el cual, a criterio personal considero que se debe de replantear, ya que hasta el momento los estudios de carácter urbano han estado circunscritos a ámbitos institucionales". 
No obstante, antecedentes de los años 1970 y tempranos 1980 citados por Marín Murillo, muestran que es hasta el final de siglo que se podría mencionar un aumento en estudios de carácter urbano. Otros estudios, aunque se suelen mencionar en otras categorías reafirmadas en el período 1985-2000, como la de género, tienen también base urbana. Un ejemplo es la tesis, presentada en 1985, de María Josefina Carlos Cabrera, Enid Mayela Pérez Castillo y Mayra Zapparoli Zecca "Machismo y socialización: un estudio de casos en familias de mujeres universitarias".

Con respecto al tema de la mujer, iniciado a partir de los años finales de los 70, con precursoras como Janina Bonilla Pignataro, Eugenia López Casas y Nancy Cartín Leiva, es otro que se aborda en este período (Otárola, 2001), al tratarse la mujer en áreas rurales y urbanas, en zonas indígenas, en sus condiciones laborales, en su salud reproductiva, y otros aspectos. En la temática de género así como de otras categorías, especialmente después de los años de 1990, se introducen enfoques posmodernistas con nuevas técnicas etnográficas y nuevas concepciones de la subjetividad en el trabajo de campo. Entre las investigaciones estuvieron las de Nancy Cartín (1991) sobre las implicaciones de las labores domésticas de la mujer para la economía campesina, la reproducción de la unidad económica campesina, el patriarcado, la participación política, y otros temas.

Existía en el Departamento de Antropología interés por separarse de Sociología y constituirse en escuela, lo que daría mayor autonomía administrativa y recursos propios para el crecimiento académico. La idea no se concretó en este período pero se abonó a su gestación. Una de las actividades que ayudó bastante a la consolidación de la idea de separarse de los sociólogos fue el Proceso de AutoevaluaciónAutorregulación que promovía el Programa Cre-Columbus, al que se adscribieron 10 universidades latinoamericanas, en el cual la Escuela de Antropología y Sociología se involucró a partir del mes de julio de 1995 y se prolongó hasta 1999. En una primera etapa, del Departamento, estuvieron en la Comisión, Ana Cecilia Arias y Olga Echeverría. En la segunda participaron Carmen Araya y Olga Echeverría como integrantes de la Comisión.

\section{El contexto sociopolítico 1985-2000}

Desde 1979, se manifiesta la aguda crisis económica que dura toda la década de los años 1980, crisis compartida con el resto de América Latina.

Continuó la concentración de la propiedad y de la riqueza, lo que ha sido favorecido por las políticas neoliberales. Ello ha resultado en la imposibilidad de reducir la pobreza, en la disminución de ingresos de las clases medias, en el incremento del trabajo informal, en la intensificación del narcotráfico y en el lavado

de dólares. 
Costa Rica participó en los movimientos migratorios centroamericanos en la década de los años 80. En los años 90, el país, y en general el mundo, ha gestionado el libre comercio.

De 1985 a 1995 se reorientaron los esfuerzos integracionistas, los que debían superar los obstáculos causantes del colapso de la integración del Mercomún al inicio de 1980. Se subscribió el tratado de libre comercio con México. Centroamérica trató de consolidarse, en los años 90, como región de paz, libertad, democracia y desarrollo, visualizada así por el Protocolo de Tegucigalpa y reafirmada por Alides (Alianza para el Desarrollo Sostenible). Esos procesos se describen en el Informe del Estado de la Región de 1999.

\section{Encuentros académicos}

1986 “Taller del Agro en Costa Rica”, realizado por el Laboratorio de Etnología, recogiendo resultados de una de las grandes preocupaciones temáticas que caracterizaron el quehacer antropológico desde fines de 1970 y durante la década de los 1980, en los que hubo preponderancia de los estudios de campesinado. 1987 Mesa Redonda "La trayectoria de la Antropología en los últimos 10 años", para conmemorar el décimo aniversario de la Escuela de Antropología y Sociología, organizada por el Laboratorio de Etnología. En los siguientes, de 1987, hubo participación de antropólogos y antropólogas, aunque no fueron organizados en el Departamento:

1987 "Primer Seminario de Tradición e Historia Oral”, Auditorio “Abelardo Bonilla”, U.C.R.

1987 Seminario sobre el Estado y Desarrollo de la Costa Atlántica de Costa Rica.

1987 "Seminario sobre el Estado y Desarrollo de la Costa Atlántica en Centroamérica 1960-1986": Organizado por CSUCA, en Limón. Antropólogos(as) participaron en ese proyecto;

1988 "Primer encuentro centroamericano de Antropología” se realizó en Turrialba. Las ponencias presentadas aparecen en el Cuaderno de Antropología No. 9 (Laboratorio de Etnología, 1993);

1989-1992 talleres en C. A. organizados por CSUCA; el de Costa Rica versó sobre tendencias teóricometodológicas. (CSUCA, 1989);

1989 "II Coloquio Paul Kirchhoff: La Etnografía de Mesoamérica Meridional y Área Circumcaribe". Asisten antropólogos y antropólogas invitados por el Instituto de Investigaciones Antropológicas de la UNAM (México);

1993 XIII Congreso Internacional de Ciencias Antropológicas y Etnológicas”. Una buena representación del Departamento asistió. Celebrado en México;

1990 Mesa Redonda "Estado de la Antropología: Presente y Futuro". 13 de noviembre. Depto. de Antropología, UCR.;

1991 “Coloquio sobre la práctica profesional de la Antropología en Costa Rica”. Véanse resúmenes en Bonilla (1994) y en Bozzoli (1994);

1991 Mesa Redonda “América Sincretismo de Culturas”. Universidad de C.R., sede de Guanacaste, Cátedra V Centenario, y Museo Nacional, 7 de marzo;

1993 “Foro sobre Racismo”. Junio, 1993. Vicerrectoría de Acción Social; 
1994 “I Congreso Centroamericano de Antropología”. El Departamento tuvo a cargo toda la organización logística, aunque contó con el apoyo de algunos colegas de otros países;

1994 "Primer Foro Estudiantil Latinoamericano de Antropología y Arqueología (FELA). Estudiantes del Departamento de Antropología crearon y organizaron el foro, contando con la participación de estudiantes de 8 países latinoamericanos;

1994 Mesa Redonda "Represa Hidroeléctrica de Boruca e Impacto”. 12 de abril de 1994, en la sede del Ministerio de Cultura (Cenac);

1994 Mesa Redonda “Conmemoración del Día de las Culturas, Asamblea Legislativa, 13 de octubre;

1995 “Primer Congreso Científico sobre Pueblos Indígenas de Costa Rica y sus Fronteras” (véase Bozzoli et al. [1998]), con asistencia de centroamericanos y centroamericanas, y de otros países externos a la región;

1996 “Mesa Redonda y presentación del libro "12 de octubre, día de las culturas: Costa Rica, una sociedad pluricultural". Salón de expresidentes, Asamblea Legislativa, 29 de octubre;

1999 "II Congreso Costarricense de Antropología y Arqueología”. UCR, Diciembre;

2000 "Segundo Congreso sobre Pueblos Indígenas".

\section{Obras representativas o influyentes}

La antropóloga Carmen Murillo Chaverri es la autora del libro "Identidades de hierro y humo. La construcción del ferrocarril al Atlántico 1870-1890” (1995), en el cual aborda las múltiples identidades generadas en la construcción del ferrocarril en Costa Rica: la nacional, la empresarial y la regional, las identidades locales, laborales y étnicas. La identidad cultural regional de la provincia de Limón reta a los investigadores de lo social por su composición multiétnica, los problemas laborales muy propios de la zona, los conflictos con el Estado. Como lo manifiesta Murillo, al deteriorarse el proyecto nacional de control sobre el ferrocarril, emerge una región construida a partir de la exaltación de la otredad cultural, la pobreza de las mayorías, la débil presencia del Estado nacional y prevalencia de intereses de extranjeros que lucran con el control de sus principales recursos. La obra precisa datos históricos que no estaban claros para la población actual, por ejemplo, la gran variedad étnico-nacional que ha estado presente en la costa compuesta de trabajadores procedentes de los países centroamericanos, sudamericanos, europeos, chinos y afroantillanos.

La antología Antropología e identidades en Centroamérica, de 1996 (Murillo Chaverri, editora) es un compendio de ponencias escogidas del Primer Congreso Centroamericano de Antropología. Los autores costarricenses incluyen a Margarita Bolaños Arquín, Carlos Borge Carvajal, Giselle Chang Vargas, Sergio Chaves Chaves, Silvia Castro Sánchez, Cecilia Dobles Trejos, Rolando Quesada Sancho, Carlos Camacho Nassar, Omar Hernández Cruz, Maureen Sánchez Pereira, María Eugenia Bozzoli de Wille, Carmen Muri1lo Chaverri, Zaira Regueyra, y Ana Lucía Calderón. La temática ilustra: historia de la Antropología; cultura y desarrollo; localidades, pueblos y naciones; género, lenguaje y símbolo; retos teóricos y metodológicos. 


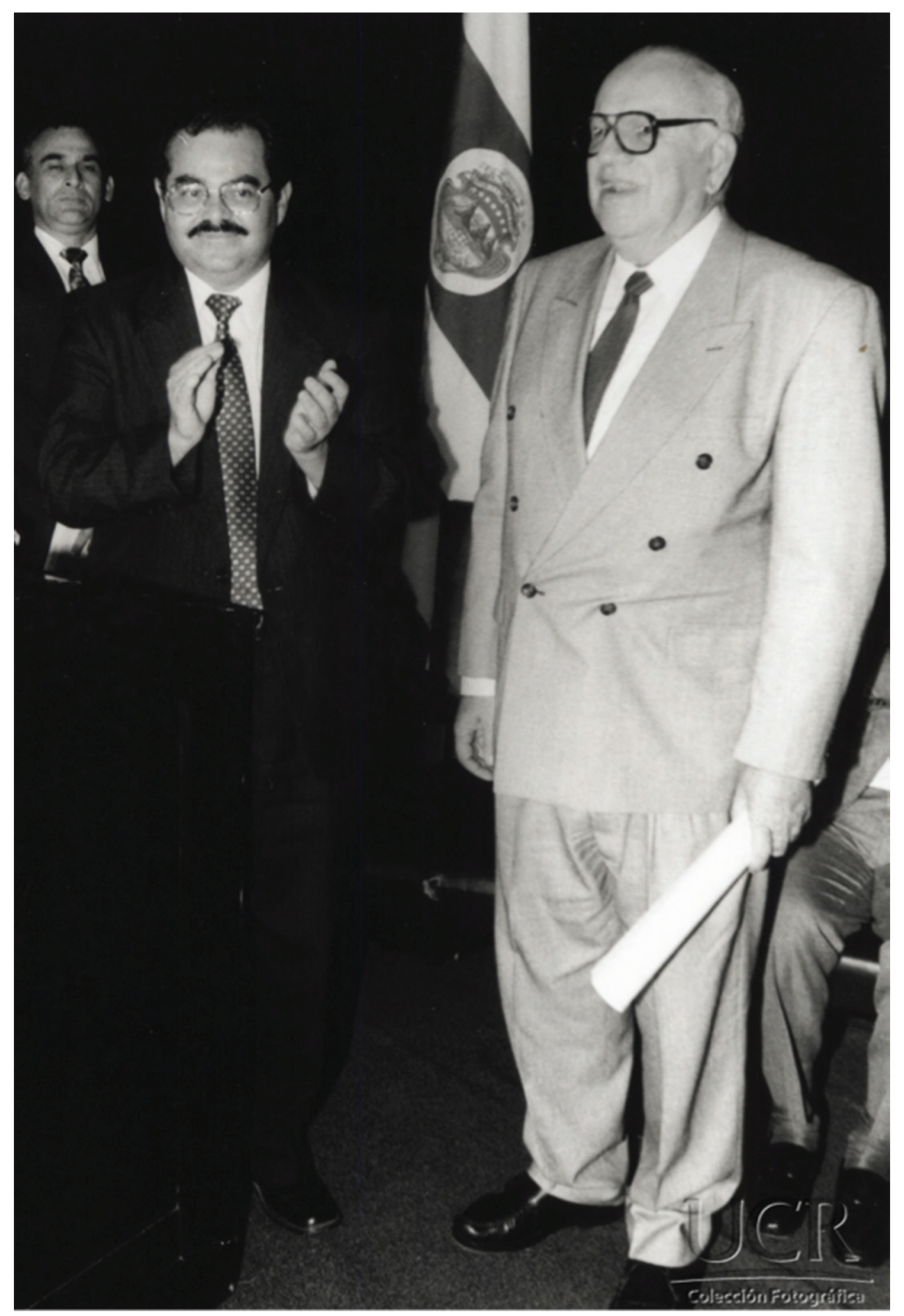

Izquierda a derecha: Doctor Garita Bonilla Luis; Meléndez Carlos. 1994. Colección fotográfica, Universidad de Costa Rica, Foto $\mathrm{N}^{\circ} 1472$ 


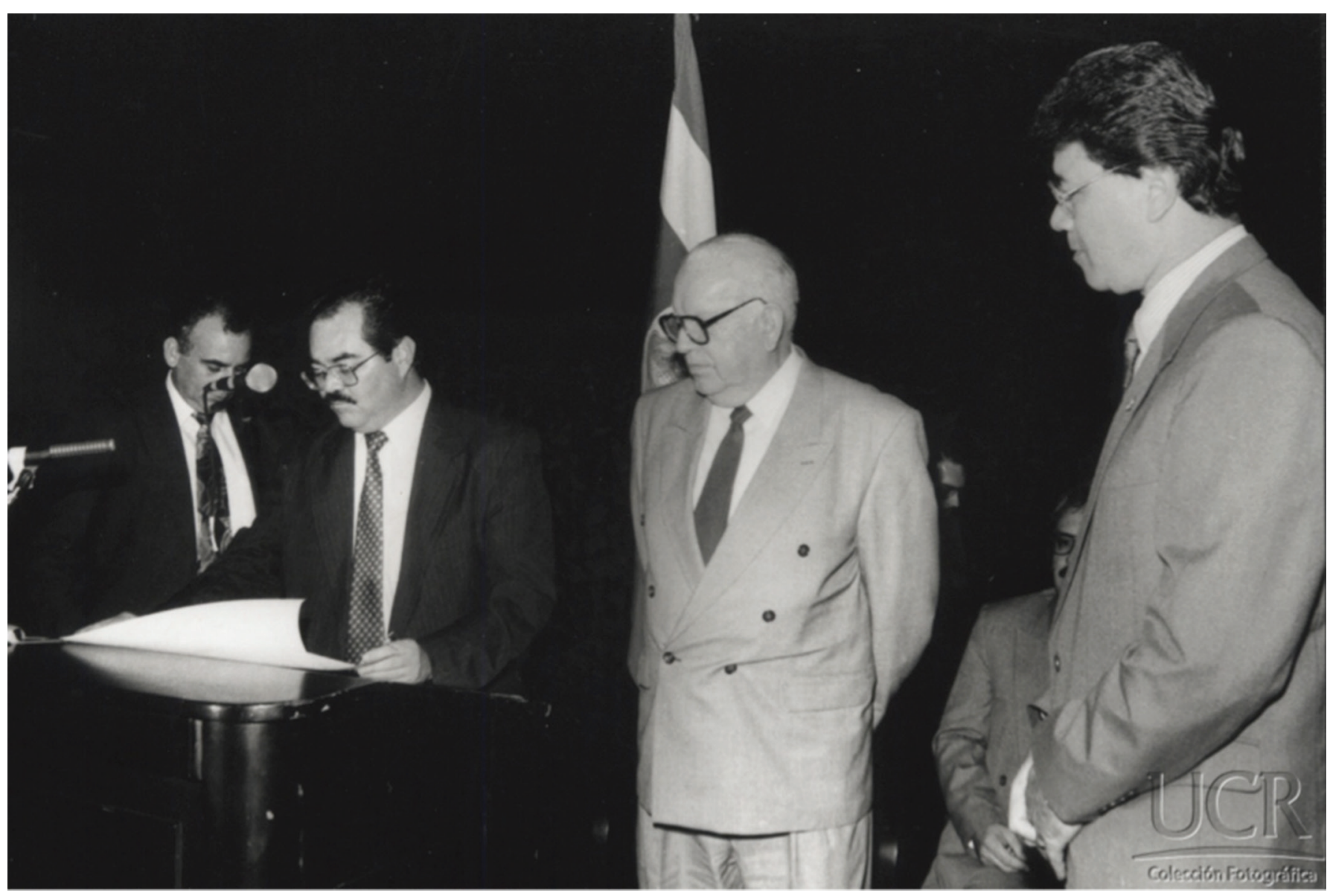

Izquierda a derecha: Brenes Luis Guillermo, Geógrafo; Doctor Garita Bonilla, Luis; Rector; Meléndez Carlos; Salazar Alfonso, Director del Consejo Universitario. Entrega del doctorado honoris causa a don Carlos Meléndez. 1994. Colección fotográfica, Universidad de Costa Rica, Foto N 1474. 


\section{La antropología como una entre las antropologías mundiales}

Preocupaciones y tendencias en el marco de la globalización como nueva revolución cultural de la humanidad, 2001-2015.

\section{Características generales}

Entre las fechas de acontecimientos de interés para caracteriza el periodo se encuentran:

2003 "III Congreso Costarricense de Antropología".

2005 "IV Congreso Costarricense de Antropología".

2005 Unesco declara tradición del boyeo y carreta costarricense "Obra maestra del patrimonio oral e intangible de la humanidad". Gestión del Ministerio de Cultura, estudio de tres antropólogas.

2006 Creación de la Escuela de Antropología.

2008 Nuevo currículum en bachillerato y licenciatura.

2009 "II Congreso Latinoamericano de Antropología”. 28-31 de julio. Escuela de Antropología. Universidad de Costa Rica.

2014 El Posgrado ha acumulado 35 graduados. El Instituto Nacional de Seguros inauguró un nuevo Museo del Jade. Parque de las Esferas de Piedra de Diquís, Patrimonio Mundial, Declaratoria de Unesco, gestión del Museo Nacional, estudio de arqueólogos(as).

2015 La Escuela tiene 34 profesores. En propiedad son 21 profesores y 13 de estos con doctorado.

2015 Traslado al nuevo edificio, Ciudadela de la Investigación, febrero 2015.

2015 X Congreso Centroamericano de Antropología, marzo.

En estos años del siglo XXI, se intensifican los procesos para enlazar más las zonas periféricas del país, con el Valle Central. En la franja caribeña, antes quizás la más apartada, aumentan las acciones de parte de antropólogos que trabajan en diferentes entidades. Por otra parte, el narcotráfico y las migraciones humanas utilizan el país, sobre todo el Caribe, como "corredor biológico", enlazando en la clandestinidad aún más el sur con el norte y reconfigurando el paisaje, las formas de vida y las estructuras de organización local. Todas esas preocupaciones se recogen en proyectos de investigación, en las ponencias presentadas en los congresos de Antropología y en las publicaciones.

Como ya lo explicábamos Bolaños y Bozzoli (2015), este período representa más intensamente las tendencias reflejadas en el desarrollo antropológico según se manifestó de 1985 al año 2000 y en períodos anteriores. Se mantienen los estudios sobre los grupos indígenas (Bozzoli, 2003), identidades, pobreza, violencia doméstica y de género, cambio social, sistemas tradicionales de producción, comunidades urbanas y rurales, entre otros. En Arqueología, Murillo Herrera (2008) ha escrito sobre el devenir de ese campo, especialmente desde el final de los años setenta en adelante. Asimismo, se aprecia constante interés en 
aspectos metodológicos y en la docencia. No obstante, el nuevo siglo se inició con cierta expectativa de asumir retos de cara al nuevo milenio: fortalecer el pensamiento antropológico, enfocar problemas urgentes y buscarles solución, como el deterioro del medio ambiente, la globalización, la dolarización, los cinturones de pobreza, la violencia y cómo incorporar perspectivas de la disciplina en la ejecución de políticas públicas. El período ha continuado el avance en los programas de formación, graduándose más antropólogos en ellos: en este primer período del siglo se graduaron alumnos de siete promociones de posgrado (maestría). El Departamento de Antropología se convirtió en Escuela en 2006; también cambia sustancialmente, a partir de2008, el currículum para el bachillerato y la licenciatura; al respecto, Rodríguez, Guevara y Román (2014) analizan los cambios en planes de estudio de la Escuela por la forma cómo reflejan nuevas orientaciones de la disciplina. Adicionalmente, el plan de estudios de la maestría fue revisado en estos años. Un ejemplo de 2011, con respecto a cómo aumenta el estudiantado, fue la siguiente : entre el I semestre de 2010 y el de 2011, en la matrícula de bachillerato y licenciatura, hay un aumento de 23 estudiantes (de 358 a 381); en el II semestre, el aumento de 2010 a 2011 es de 19 estudiantes (de 338 a 357). Considerando además el posgrado, la Escuela estaba atendiendo alrededor de 400 estudiantes anualmente. Entre 2001 y 2011 se graduaron en la Maestría 32 estudiantes (por énfasis, 4 en Arqueología, 3 en Pueblos Indígenas, 25 en Antropología Social). Estos fueron resultado de seis promociones a partir de marzo de 1998. La sétima promoción inició lecciones en agosto de 2012. Otro ejemplo del crecimiento, en 2014 el posgrado había acumulado un total de 35 graduados. Elaboraron 25 de ellos su tesis en el campo de la Antropología Social; 9 de las tesis versaron sobre materia arqueológica y una en Antropología Biológica. Seis de los graduados son extranjeros: dos de Panamá (uno de ellos de Kuna Yala), uno de Puerto Rico, dos de España, una de Canadá y uno de Estados Unidos. Otros países representados con estudiantes en el programa han sido Nicaragua, Honduras, El Salvador y Francia. En 2014 están matriculados tres estudiantes nicaragüenses y una panameña. Entre los temas trabajados se encuentra etnología indígena (religión, proyectos de desarrollo, políticas públicas y neoindigenismo, alimentación, identidad), cultura urbana (contaminación ambiental, modificación del cuerpo mediante prácticas de piercing, marginalidad), género, identidad rural, antropología política, violencia, salud, futbol, migrantes, patrimonio, historia antigua de los pueblos indígenas y antropología biológica. El profesorado en propiedad de la Escuela, en 2015, es de 21 profesores (13 con doctorado, 7 con maestría, y una egresada de maestría). De los profesores con maestría, cursan el doctorado 3. Los doctorados provienen de la Universidad de Costa Rica y de México, Estados Unidos, España, Francia y Brasil. Están por concluirse uno de Australia, y uno de España) . En el primer semestre de 1915, hay además 13 profesores interinos impartiendo cursos de la Escuela. El número de estos profesores sin plaza fija con que cuenta la Escuela es variable semestre tras semestre, debido a los cambios en torno a número de estudiantes, cursos y grupos que se abren; además, también depende de la cantidad de tiempo docente con que cuente cada profesor en propiedad, pues las cargas académicas de estos se dedican también a investigación y acción social.

Al concluir este periodo, el país cuenta con programas de formación académica (Licenciatura y Maestría) en Antropología Social y Arqueología, en la UCR, y con cursos en diferentes campos de la disciplina, tanto en la UCR -incluidas sus sedes regionales- como en las otras tres universidades públicas (UNA, UNED, TEC). 
La era de la globalización -se suele marcar a partir de la caída del muro de Berlín en 1989, por la eliminación de barreras al comercio en el ámbito global- ha traído un cambio en cuanto a la relación de las antropologías de países en vías de desarrollo con las antropologías de países desarrollados. Esto es de particular interés debido a la preocupación de la Antropología latinoamericana por la hegemonía de los países desarrollados sobre la teoría y el ejercicio de la disciplina antropológica, y por la necesidad de desarrollar visiones propias. En la década de los años 1970 fue más evidente el malestar con las corrientes hegemónicas en la disciplina; además, depender del conocimiento de otras regiones no se ha estimado apropiado para la integridad de las culturas e identidades nacionales; persiste la inquietud por la pertinencia de hallazgos ajenos para las realidades locales.

En general, en Costa Rica, la Antropología ha tenido algunas de las características que Esteban Krotz (1996) señaló para las antropologías "del sur", tanto coincidentes como complementarias con las que había señalado Roberto Cardoso de Oliveira, desde Brasil, para las antropologías periféricas. Sin embargo, conforme ha avanzado la era de la globalización, ha surgido en América del Sur una nueva visión de la hegemonía de las antropologías de países desarrollados sobre las de aquellos en desarrollo. En este sentido es reveladora la posición de Gustavo Linz Ribeiro. Este autor ha declarado (2008, p. 73): "De hecho, el mundo globalizado es el escenario perfecto para que florezca la antropología ya que una de las lecciones básicas de la disciplina es el respeto a la diferencia. Una disciplina que elogia la pluralidad y la diversidad precisa promover tales dinámicas en su propio medio. Este es el momento ideal para las antropologías mundiales".

Linz Ribeiro se refiere a transformaciones que alteran las antropologías hegemónicas, entre ellas: (a) tecnologías digitales e internet; (b) emergencia de una comunidad transnacional virtual; (c) creación y apoyo de una sociedad civil global; (d) nuevas migraciones internacionales; (e) redefinición del papel de la distancia de los sujetos etnográficos; (f) los pueblos exóticos convertidos en vecinos; (g) nuevas transformaciones generadoras de una crisis de representación: por ejemplo, el multiculturalismo y movimientos políticos "nativos", son factores que transforman también a las antropologías hegemónicas; (h) surgimiento de corrientes teóricas que no tenían el pecado original de cooperación con el colonialismo; (i) el presente como momento de reinvención de la Antropología, por los cambios en las relaciones entre antropólogos ubicados en diferentes localidades del sistema mundial. Concluye que (j) una mayor visibilidad internacional de las antropologías funciona como prerrequisito para que exista una comunidad más diversificada e igualitaria de antropólogos mundiales y formas más complejas de crear y circular teoría y conocimiento en el nivel global. En otras palabras, G. Linz Ribeiro y otros autores señalan condiciones favorables a la igualdad entre todas las antropologías que se están produciendo en el siglo XXI.

\section{El contexto sociopolítico centroamericano, 2001-2015}

El cambio de siglo encontró al país en democracia y estabilidad política; paralelamente se gestan intensos procesos migratorios, narcotráfico, drogas, creciente desigualdad, pobreza e inseguridad, entre otros 
aspectos que se pueden destacar. En el quehacer económico, el país continuó desarrollando propuestas de integración económica, negociaciones para convenios internacionales, y estableciendo la vigencia de nuevos tratados de comercio. La esperanza de vida sigue aumentando, y el reconocimiento de la multiculturalidad; el país se ha rezagado en combate a la pobreza, en mejoras en educación y salud, ha habido aumento del empleo precario y la economía informal, se ha constatado que disminuir la pobreza no reduce la desigualdad, no han cedido las amenazas al patrimonio natural. En 2013, aún se estaban firmando acuerdos de libre comercio con distintos países. El único acuerdo de ese tipo que generó oposición de parte de diversos sectores, fue el denominado Cafta, por sus siglas en inglés, a saber, el TLC con la República Dominicana, Estados Unidos y los países centroamericanos. Polarizó la sociedad -proceso entre diciembre de 2003 y octubre de 2007-, al punto que se llevó la aprobación de ese TLC a un referéndum (Bozzoli, 2005-2006).

\section{Encuentros académicos}

2001 “Congreso de Pueblos Indígenas”, 18, 19 y 20 de abril. UCR.

2002 "II Congreso sobre Pueblos Indígenas de Costa Rica y sus Fronteras".

2002 “Conferencia Internacional Diversidad Cultural y Mundialización”, 17-18 de diciembre, UCR. E1 Departamento no la organizó pero asistimos antropólogos y antropólogas.

2003 “III Congreso Costarricense de Antropología”. Dedicado a Carlos H. Aguilar P. y a

María E. Bozzoli. Museo Nacional de Costa Rica, del 2 al 4 de diciembre.

2004 “Teoría y práctica en la etnografía de los pueblos talamanqueños de Costa Rica”. Instituto de Investigaciones Antropológicas y el Instituto de Investigaciones Filológicas de la Universidad Nacional Autónoma Metropolitana, de México; participación de tres profesores del Departamento de Antropología en el marco de acuerdos de intercambio académico UCR-UNAM, negociados por el Programa de Posgrado en Antropología.

2004-2015 Los congresos de la Red Centroamericana de Antropología han continuado en forma regular, con sede en distintos países, con la colaboración costarricense en organización (reuniones previas a los congresos), y participación de profesores y de estudiantes de la Escuela Antropología.

2005 "IV Congreso Costarricense de Antropología" celebrado en la UNED, del 6 al 8 de diciembre de (véase información sobre este Congreso en el anexo I).

2006 "Exploración de las relaciones históricas entre los pueblos indígenas de la Baja América Central y del norte de Suramérica"; Simposio organizado por el Posgrado en Antropología para discutir la pertinencia de la propuesta de una Área Histórica Chibcha, hecha por Oscar Fonseca, con base en interpretaciones arqueológicas y en los trabajos de Ramiro Barrantes (Antropología Biológica - Escuela de Biología) y Adolfo Constela -Lingüística, Facultad de Letras).

2009 "II Congreso Latinoamericano de Antropología”. 28-31 de julio. Escuela de Antropología. Universidad de Costa Rica.

2010 "Primer Congreso Iberoamericano de Patrimonio Cultural". Convocado por la Universidad de Costa Rica y la Universidad Autónoma de la Ciudad de México, UACM. Hubo participación de la Escuela en organización y en ponencias. 
2010 “Encuentro Centroamericano de Estudiantes de Antropología”, 27-30 de julio, 2010. Universidad de Costa Rica.

2012 "Contribuciones del Dr. Miguel Snarskis a la Arqueología Costarricense"; con invitados nacionales e internacionales, organizado por la Escuela y el Posgrado en Antropología.

2012 “Jornadas de Investigación Antropológica, A la memoria de Rolando Quesada Sancho”. Organizadas por la Escuela y el Posgrado en Antropología.

2013 "Foro Estudiantil Latinoamericano de Antropología y Arqueología (FELA). 19 años después de su creación, el estudiantado de Antropología organizó de nuevo el evento, contando una participación de estudiantes de países latinoamericanos.

2013 "Primera Muestra de Cine Etnográfico", con Brasil como país invitado, actividad del Laboratorio de Etnología.

2015 "X Congreso centroamericano de Antropología", celebrado en Mérida, Yucatán, con participación importante de la Escuela, en organización previa y en ponencias de profesores y estudiantes.

\section{Obras representativas o influyentes}

Como reflexiones de lo que ha sido antes y debería ser a futuro, se encuentra la obra Retos y perspectivas de la Antropología Social y la Arqueología en Costa Rica (Araya y Bolaños, 2004) con trabajos de 24 colegas.

"Boyeros, bueyes y carretas. Por la senda del patrimonio intangible" de Cecilia Dobles, Carmen Murillo y Giselle Chang (2008), es voluminosa; aborda el boyeo y la carreta en su pasado, presente y posibilidades futuras; las etapas históricas, con una época de oro en el siglo XIX; los usos en medios rurales y urbanos; las particularidades de los bueyes; la confección artesanal; el boyeo como actividad laboral y rasgos de los boyeros; el lugar de la tríada del boyeo, los bueyes y las carretas reflejado en las artes mediante el costumbrismo; la tríada en la política; colores, sonidos y creatividad del lenguaje utilizados en ese complejo referido a una forma de transporte y a un quehacer costarricense. Aborda contradicciones, como la de incorporarse el país a los denominados avances mundiales urbano industriales mientras que el ser nacional se concibe fundamentado en la vida y virtudes rurales. El simbolismo de la tríada es amplísimo. Esta obra está basada en fuentes de archivo y en muchísimas entrevistas, por ejemplo, 87 boyeros y boyeras, 21 artesanos de carretas y yugos, ocho amansadores y una amansadora, 33 organizadores y organizadoras de desfiles, y 30 otros y otras que incluyen profesionales, espectadores, comerciantes, autoridades locales, etc. También está basada en observaciones propias y en la extensa bibliografía que se ha dado sobre el tema; se ilustra profusamente con mapas, gráficos, cuadros y figuras. La metodología fue impecable. La investigación se realizó para presentar la candidatura de Costa Rica ante la Unesco para que el boyeo fuera declarado patri- 
monio oral e inmaterial mundial. Así, en noviembre de 2005, la Unesco declaró la tradición del boyeo y la carreta costarricense "Obra maestra del patrimonio oral e intangible de la humanidad".

Otro libro sobresaliente del período es "San José: de "París en miniatura" al malestar en la ciudad. Medios de comunicación e imaginarios urbanos", de María del Carmen Araya (2010), resultado de una investigación llevada a cabo en la capital costarricense entre 2000 y 2006, sobre los imaginarios urbanos elaborados por varios sectores: económicos, políticos, urbanistas, residentes de vecindarios, publicistas y periodistas. La realidad josefina de principios del siglo XXI ha creado seis imaginarios que plantean tesis, impactan ámbitos, son movidos por deseos, fantasías o miedos, y todos tienen un papel que cumplir en la dinámica del capitalismo. Esos imaginarios son la ciudad simbólicamente polarizada entre el este y el oeste, la cultura de y para el consumo, el pastiche de interpretaciones de la ciudad, la noción de caos que se busca eliminar mediante el retorno al casco urbano, el centro de la ciudad deshabitado y temido, la repoblación del casco central como retorno a la ciudad deseada, soñada y nostálgica. El enfoque de Araya no es común, puede parecer literario. Sin embargo, aborda objetivamente realidades propias de San José, de tal manera que quien viva en esta ciudad las reconoce en su libro, tal como sucedería si la obra fuera únicamente una etnografía convencional.

Por la rama de Arqueología se puede citar Cambio Social Precolombino en San Ramón de Alajuela, Costa Rica, de Mauricio Murillo (2011). El autor contrasta dos tendencias en la explicación de los procesos del cambio social en la Centroamérica precolombina: en una se encuentran los trabajos de investigación que han enfatizado en las interacciones con Mesoamérica y América del Sur como principal origen de las transformaciones culturales en el área istmo-colombiana. En la otra tendencia se encuentran los estudios que resaltan factores locales que tuvieron peso en las orientaciones del cambio y contribuyeron de este modo a las configuraciones sociopolíticas de las sociedades del sur de Centroamérica. Para destacar esta tendencia, quienes investigan recurren a una distinción conceptual entre la cultura material, directamente observable, como son artefactos, diseños artísticos, arquitectura, escultura, productos alimenticios y otros rasgos, y, por otra parte, la organización social compuesta de instituciones políticas, religiosas y económicas. La visión desde el análisis de la cultura material pone el énfasis en la difusión, o en factores externos, y en reconstruir horizontes de rasgos; la visión desde el análisis de la estructura social privilegia la identificación de elementos de desarrollo propio o dinamismo interno y reconstruir patrones de actividades y de organización social. Este último enfoque es el adoptado en la investigación de Murillo en la región de San Ramón de Alajuela. San Ramón ya registraba estudios anteriores de parte de varios arqueólogos y arqueólogas, los que son tomados en cuenta en esta obra para insertarlos en las premisas metodológicas seguidas por Murillo, conducentes a una explicación de tipo regional, para trayectorias de cambio en una extensión espacial amplia y un lapso de tiempo de largo plazo. En este sentido, el libro, en la arqueología costarricense, representa una contribución innovadora. 


\section{Resumen}

En el primer período, en el país, se generó literatura histórica y periodística relacionada con los orígenes de la población y sus características raciales y culturales, así como con sus capacidades para orientarse hacia el progreso. El lugar de los indígenas en la construcción e identidad de la república figuró tangencialmente en el pensamiento intelectual del período 1880-1945. La institución que lleva a cabo estudios relacionados con lo indígena, arqueológicos y etnográficos es el Museo Nacional, fundado en 1887. En 1940, se decretó la creación de la Universidad de Costa Rica y de la Academia de Geografía e Historia. Entre las Facultades de la UCR se incluye la de Filosofía y Letras, y dentro de esta, cursos de Etnología y Arqueología.

En el segundo período, 1945-1970, se pusieron en práctica políticas de indigenismo. El tema del cambio social y político nacional fue novedoso sobre todo al final del período. Se promovieron los programas docentes. Los antropólogos en los primeros programas se formaron fuera de Costa Rica. El Consejo Superior Universitario Centroamericano (CSUCA) realizó un proyecto conducente a mejorar la enseñanza en los cursos universitarios introductorios. En la Universidad de Costa Rica, se creó la Facultad de Ciencias y Letras, dentro de esta el Departamento de Historia y Geografía, y posteriormente Ciencias del Hombre.

De 1970 a 1985, los temas sobresalientes de discusión involucran el subdesarrollo, la proletarización, insurrecciones campesinas, racismo, violencia, cambios gubernamentales, reforma y revolución. Cedal, de la Fundación Friedrich Ebert, y CSUCA, patrocinaron encuentros de científicos sociales, en los que participaron antropólogos de los países centroamericanos y del resto de América Latina. En Cedal se trataron temas de indigenismo, de docencia y de patrimonio cultural. El CSUCA promovió el debate sobre el papel de las Ciencias Sociales en Centroamérica y un proyecto de investigación pionero en su carácter centroamericano: "Estado y Desarrollo de la Costa Atlántica". Se creó en la UCR la Facultad de Ciencias Sociales. El Departamento de Ciencias del Hombre, antes en Ciencias y Letras, pasó a ser parte de Ciencias Sociales a partir de 1973, como escuela. En esta última Facultad se creó la Escuela de Antropología y Sociología en 1977 la cual incluyó a la Antropología como Departamento.

De 1985 a 2000 se reflexionó más explícitamente acerca de la necesidad de desarrollar la antropología mediante esfuerzos propios en lo organizativo, en lo metodológico y en lo teórico. Las condiciones de la vida urbana, las de las mujeres y los migrantes se analizan en las investigaciones y en los cursos. Las primeras promociones de graduados sobrepasaron la capacidad de la academia de acogerlos en lo laboral. Se abrieron campo en su sociedad. Al efecto, las ONG cumplieron un papel en absorber estos profesionales, así como las instituciones gubernamentales. La UCR, y otras universidades públicas centroamericanas y del sur de México, fundaron la Red Centroamericana de Antropología. En el período se nota expansión de la docencia de la Antropología en cursos para el grado y para otras carreras; al final del período se planifica el posgrado. 
En el siglo XXI, la globalización trajo un cambio de perspectiva sobre las relaciones de "las antropologías del sur” y las de los países hegemónicos. El Departamento de Antropología continuó formando parte de la Escuela de Antropología y Sociología hasta 2005. La Escuela de Antropología, en la Facultad de Ciencias Sociales, se aprueba en 2006 en la Asamblea Universitaria.

En el presente documento sobre el desarrollo de la Antropología en el país, se han señalado diferentes maneras de relacionarse con las antropologías europea, norteamericana, y latinoamericana; en este último caso, especialmente con la mexicana. Una manera de vincularse con el exterior fue la formación de profesionales en el extranjero; otra ocurrió por los estudios antropológicos locales de parte de eruditos externos, quienes se relacionaron con instituciones y estudiosos nacionales. No obstante, en este trabajo el abordaje histórico del desarrollo de la disciplina enfatizó en el esfuerzo nacional. La disciplina tuvo crecimiento continuo paralelo al crecimiento de la UCR: aumento de profesionales y de graduados; la carrera progresó de un bachillerato a un programa de posgrado; se tuvo un aumento sostenido de matrícula en todos los niveles, en cursos, en programas y proyectos de investigación, en acción social (Trabajo Comunal Universitario, Extensión Docente, comisiones externas y otras formas de colaboración cívica con el país); cada período tuvo producción bibliográfica considerable, aunque en estas páginas solo se mencionaron algunos ejemplos; las crecientes frecuencias de encuentros académicos no solo mostraron los avances nacionales en la disciplina, sino que facilitaron los enlaces internacionales. La Antropología puso de relieve las formas de la diversidad cultural que conformaban el país; los estudios antropológicos influyeron y han estado a su vez mediados por las estrategias nacionales de desarrollo.

En lo institucional, la Antropología costarricense se ha desarrollado durante 128 años (1887-2015), pero especialmente en 53 años a partir de 1962; se ha caracterizado por la vinculación entre sí de la docencia, la investigación y las acciones relacionadas con el logro del bienestar de las poblaciones; por la misma razón, ha predominado la preferencia por el estudio de las gentes en condiciones de pobreza y exclusión en el contexto económico y político: en lo económico, el país visto en el ámbito mundial, es de recursos económicos limitados; en lo político, se han dado las formas de gobierno favorables, las indiferentes y de vez en cuando las adversas a la disciplina en diferentes momentos; convicciones políticas han acompañado el desempeño profesional. Otro rasgo es la intensificación de las relaciones con las antropologías del Istmo, especialmente a partir de 1988.

Compartimos algunas de las características de las denominadas "antropologías del sur" en el tanto que las ramas de la disciplina antropológica se han desarrollado en una de las regiones en vías de desarrollo del mundo. Se propuso que la globalización ha cambiado la naturaleza de las diferencias entre las antropologías de países desarrollados y las de aquellos en desarrollo y una consecuencia son las relaciones de igualdad entre estas antropologías. 
No es posible predecir los rumbos que tomará la antropología costarricense en los próximos años. En lo que respecta a la Escuela en la UCR, se puede postular un período que iniciaría en 2015 con los siguientes hechos: (1) En febrero inició el traslado desde el Edificio de Ciencias Sociales en la Ciudad Rodrigo Facio al nuevo edificio en la Ciudad de la Investigación. La Antropología, en sus funciones administrativas, tuvo asiento primero en lo que fue el Edificio de Ciencias y Letras, el que luego fue exclusivo para los Estudios Generales. Allí la Sección y Departamento de Antropología tuvieron oficina de Dirección y oficinas de profesores, al frente del Auditorio Abelardo Bonilla; otras oficinas estaban en el cuarto piso, el mismo del primer espacio que tuvo el Laboratorio de Arqueología. En 1979 se trasladó todo lo concerniente a la Administración de Antropología -salvo el Laboratorio de Arqueología que ya ocupaba un ala de la Biblioteca Carlos Monge- al vecino edificio de aulas, que se nombró luego Edificio de Ciencias Sociales, hasta la mencionada fecha de febrero de 2015. El nuevo edificio en la Ciudadela de la Investigación aporta un amplio espacio para las actividades académicas, muy amplio en relación con el de las instalaciones previas. Eso deberá suponer un estímulo para intensificar e innovar en actividades. (2) En 2015, la Escuela se abocó a formalizar una propuesta para crear el Centro de Investigaciones, la cual fue aprobada en la Asamblea de Escuela el miércoles 18 de marzo de 2015. (3) En el primer semestre de 2015, el programa de posgrado aprobó una propuesta de maestría profesional, para iniciar en agosto del mismo año. (4) En marzo de 2015, se aprobó en el X Congreso de la Red Centroamericana de Antropología, que la Escuela organizará el XI Congreso en 2017. Los cuatro acontecimientos justificarían pensar en el inicio de un sexto período ¿de aproximadamente quince años, cómo el tercero, cuarto y quinto precedentes?

Se pueden señalar áreas en las que la Región enfrenta desafíos y recomendar que la disciplina se siga desarrollando para contribuir con soluciones: la pobreza afecta a casi una cuarta parte de la población $(22,4$ \% de hogares y 6.7 \% extrema, en 2014); también son áreas críticas la desigualdad y la exclusión social; para enfrentar las amenazas que han estado actuando, como las del crimen organizado, las de los efectos adversos del cambio climático, y las de las crisis económicas, es útil continuar con enfoques ya probados en estudios existentes, al mismo tiempo que con la búsqueda de nuevos abordajes. Las antropólogas y antropólogos cuentan en su disciplina con recursos metodológicos y conceptuales para aportar a los cambios necesarios, en aspectos que los reclaman, tales como el alcance de la equidad de género; la observancia de los derechos humanos; la promoción de los valores positivos implicados en la diversidad cultural; aplicar el desarrollo sostenible; planificar para la supervivencia alimentaria; mantener la convivencia en paz; reducir o eliminar toda forma de relación violenta; combate de la precariedad laboral y atención a las poblaciones vulnerables. La Antropología debe seguir aportando conocimientos que expliquen la condición humana, y puede seguir siendo coadyuvante en el logro de una sociedad de características óptimas para el desarrollo de la humanidad. 


\section{Referencias bibliográficas}

Adams, J. y Margarita B. (1996). Aproximación histórica al desarrollo de la antropología norteamericana en Centroamérica: 1930-1990. En C. Murillo (ed.), Antropología e identidades en Centroamérica (pp. 25-43). San José: Departamento de Antropología, Escuela de Antropología y Sociología, Universidad de Costa Rica.

Aguilar, C. (1953). Retes, un depósito arqueológico de las faldas del Irazú. Sección tesis de grado y ensayos, 5.

Aguilar, C. (1965). Religión y magia entre los indios de Costa Rica de origen sureño. Serie Historia y Geografía, 6.

Alfaro, A. (1923). El Delfín del Corubucí. San José: Lehmann.

Alvarenga, P. (2012). La construcción de la raza en la Centroamérica de las primeras décadas del siglo XX. Anuario de Estudios Centroamericanos, 38, 11-40.

André-Bonnet, J. L. (1919). Lo que sería una escuela de Antropología en Costa Rica. Revista de Costa Rica, I, 319-321.

Anuario de Estudios Centroamericanos. (1974(1); 1976(2); 1977(3), (1979(4), 1980(5); 1981(6). Instituto de Investigaciones Sociales, Universidad de Costa Rica: Editorial Universidad de Costa Rica.

Araya, M. del C. y Bolaños, M. (comp.). (2004). Retos y perspectivas de la Antropología Social y la Arqueología en Costa Rica. San José: EUCR.

Araya, M. del C. (2010). San José. De "París en miniatura" al malestar de la ciudad. Medios de comunicación e imaginarios urbanos. San José: EUNED.

Araya, M. del C. y Salgado, S. (comp.). (2008). Contribuciones del Dr. Michael J. Snarskis a la arqueología costarricense. San José: SIEDIN.

Arias, A. C., Bozzoli, M. E., Chang, G. y Rojas, M. (eds). (2003). II Congreso sobre pueblo indígenas. Del conocimiento ancestral al conocimiento actual; visión de lo indígena en el umbral del siglo XXI. San José: SIEDIN.

Arias, A. C. (2013). La Arqueología en Costa Rica: Reflexiones en torno a la obra de Carlos H. Aguilar Piedra. San José: Departamento de Antropología, Escuela de Antropología y Sociología, Universidad de Costa Rica.

Bolaños, M. (1993). El estado actual de la antropología en Costa Rica. Cuadernos de Antropología, 9, 59-71.

Bolaños, M. (1998). La colonia y la resistencia indígena en la configuración económica y cultural de las sociedades costarricenses y guatemalteca del siglo XIX (pp. 153-172). En M. E. Bozzoli, R. Barrantes, D. Obando y M. Rojas (comps), Primer Congreso Cientifico sobre pueblos indígenas de Costa Rica y sus fronteras. Memoria. San José: UNICEF-EUNED-EUCR. 
Bolaños, M. (1999). Anthropological Approaches in U.S. Studies of Central America, 1930-1970: Implications for Central American Anthropology (Tesis de doctorado inédita). University of Kansas, Kansas, Estados Unidos.

Bolaños, M. (2001a). Retos de la Antropología Centroamericana en el presente decenio. En G. Mejía y R. Rivas (coords), Antropología Salvadoreña ante el nuevo milenio: Un acercamiento al pensamiento antropológico centroamericano (pp. 31-45). Encuentro de la Red Centroamericana de Antropología. San Salvador: Universidad Tecnológica de El Salvador.

Bolaños, M. (2001b). La Antropología costarricense en el marco del contexto centroamericano de finales del siglo XX. Reflexiones, 80(2), 141-147.

Bolaños, M. (2002). The Costa Rican Social Anthropology in the Central American Context at the end of Twentieth Century. Journal of Practicing Anthropology, 24(4), 17-21.

Bolaños, M. y Bozzoli, M. E. (2002). Aportes de la Antropología mexicana para la comprensión de Centroamérica: Reflexiones desde la Antropología Social costarricense. Presentado en el IV Congreso Centroamericano de Antropología. Xalapa, Veracruz, México.

Bolaños, M. (2010). A quince años del trabajo de la Red Centroamericana de Antropología: Hacia la integración de saberes, por una Centroamérica sin pobreza, sin violencia y culturalmente diversa. En G. Ascencio (ed.), La Antropología en Centroamérica: Reflexiones y perspectivas (pp. 53-75). Chiapas, México: UNICACH-UNAM.

Bolaños, M. y Bozzoli, M. E. (2015). Introducción al estudio del desarrollo de la Antropología centroamericana (1880-2013). San José: EUCR.

Bolaños, M. y Carvajal, K. (2006). Relaciones entre la Universidad de Costa Rica y el Museo Nacional: Pericias de la investigación antropológica costarricense. Cuadernos de Antropología, 16: 125-137.

Bonilla, J. (1994). Historia del Departamento de Antropología. Revista de Ciencias Sociales, 64: 85-95.

Bozzoli, M. E. (1973). Informe del Comité de Antropología del Instituto Panamericano de Geografía e Historia. Sección Nacional, Costa Rica, 1972. Boletín Bibliográfico de Antropología Americana (19731979), 36(45): 30-31.

Bozzoli, M. E. (1994). La antropología aplicada en Costa Rica y Centroamérica. Reflexiones, (22), 3-21.

Bozzoli, M. E., Barrantes R., Obando, D. y Rojas, M. (comps). (1998). Primer Congreso Cientifico sobre Pueblos Indígenas de Costa Rica y sus fronteras. Memoria. San José: EUNED.

Bozzoli, M. E. (2000). La obra de Eugenio Fonseca Tortós. Tomo III Selección de la obra sociológica de Eugenio Fonseca Tortós. En J. Rovira, J. L. Vega y F. Bolaños (eds), Estratificación social, movilidad social y planificación familiar: Ensayos en honor a Fonseca Tortós (pp. 783-795). San José: EUNED-EUCR.

Bozzoli, M. E. (2003). Vías hacia el conocimiento: los estudios indígenas en Costa Rica. En A. C. Arias (ed.), II Congreso sobre Pueblos Indígenas. Del conocimiento ancestral al conocimiento actual: visión de lo indígena en el umbral del siglo XXI (pp. 1-9) San José: SIEDIN.

Bozzoli, M. E. (2005-2006). El contexto contemporáneo de los Tratados de Libre Comercio y la acción universitaria. Repertorio Científico, 9(1), 12-20. 
Bozzoli, M. E. (2013). José Fidel Tristán, con particular referencia a sus aportes etnográficos. Revista del Archivo Nacional, LXXVII (1-12): 59-122.

Carlos, M. J., Pérez, E. y Zapparoli, M. I. (1985). Machismo y socialización: Un estudio de casos en familias de mujeres universitarias (Tesis de licenciatura inédita). Universidad de Costa Rica, San José, Costa Rica.

Cartín, N. (1991). El patriarcado en la familia campesina y su influencia en las prácticas participativas de la mujer. Université Catholique de Louvain, Bélgica.

Chang, G., González, F. (1981). Cultura popular tradicional: Fundamento de la identidad nacional. San José: EUNED.

Chapman, A. M. (1960). Los Nicarao y los Chorotega según las fuentes históricas. San José: Serie Historia y Geografía 4, Universidad de Costa Rica

Constenla, A. (1997). Semblanza del Dr. Víctor Manuel Arroyo Soto. En M. Rojas, (ed.), Memoria del VI Congreso Nacional de Filología, Lingüística y Literatura Víctor Manuel Arroyo (pp. 13-21). Heredia: Universidad Nacional Autónoma.

Comas, J. (1969). La antropología en la formación de profesionistas no antropólogos. América Indígena, XXIX(3): 711-726.

Congreso Indigenista Interamericano. (1959). Acta final del cuarto Congreso Indigenista Interamericano: Celebrado en Guatemala 16-26 de mayo de 1959. México: Instituto Indigenista Interamericano.

Corrales, F. (1999). El pasado negado: El desarrollo de la arqueología costarricense y la identidad nacional. Vinculos, 24 (1-2): 1-27.

Consejo Superior Universitario Centroamericano (CSUCA). (1988). Estudios Sociales Centroamericanos 1, (48, Set-Dic.).

Consejo Superior Universitario Centroamericano (CSUCA). (1989). Plan Antropología 1989-1990. Guatemala: Editorial Universitaria, Universidad de San Carlos de Guatemala.

Cuadernos de Antropología. (1993). La antropología en Centroamérica. Cuadernos de Antropología (9, enero-junio). Laboratorio de Etnología. Universidad de Costa Rica.

Dobles, C., Murillo C. y Chang, G. (2008). Boyeros, bueyes y carretas. Por la senda del patrimonio intangible. San José: Editorial de la Universidad de Costa Rica

ENA, Escuela Nacional de Antropología e Historia. (1944). Anuario ENA, México.

Fonseca, E. (1996). Centroamérica: Su historia. San José: FLACSO, EDUCA.

Herrera, M. (1993). Panorama general del desarrollo de la Antropología en las instituciones públicas y privadas de Costa Rica. Cuadernos de Antropología, 73-86.

Ibarra, E. (2010). La Antropología Social y la Arqueología en la Facultad de Ciencias Sociales de la Universidad de Costa Rica (1967-2009). Reflexiones, 89(1), 163-173.

Instituto Indigenista Interamericano. (1948). Boletín Indigenista (Suplemento), 8(1).

Instituto Indigenista Interamericano. (1967). Reunión para la integración de la enseñanza con las investigaciones antropológicas. Anuario Indigenista, XXVII.

Instituto Indigenista Interamericano. (1973). América Indígena, XXXIII(2). 
Instituto Indigenista Interamericano. (1975). América Indígena, XXXV(4).

Instituto Indigenista Interamericano. (1980). América Indígena. 40 años Índice General (1940-1980). México. Compilador Elio Masferrer. Serie SEDIAL1.

Krotz, E. (1996). Las antropologías del sur: Características y perspectivas de las ciencias antropológicas en Latinoamérica. En C. Murillo (ed.), Antropología e identidades en Centroamérica (pp. 15-24). San José: Departamento de Antropología, Escuela de Antropología y Sociología, Universidad de Costa Rica.

Laboratorio de Etnología (1993). Cuadernos de Antropología. (9, enero-junio). Departamento de Antropología de la Universidad de Costa Rica.

Lara, R. (2004). Ensayos de Antropología y Literatura. San José: Departamento de Antropología, Escuela de Antropología y Sociología, Universidad de Costa Rica.

Lines, J. A. (1942). Un baby-face en Costa Rica. En Sociedad Mexicana de Antropología, Mayas y Olmecas: Segunda Reunión de la Mesa Redonda sobre problemas antropológicos de México y Centro América - Tuxtla Guitérrez, Chiapas (p. 54). México D.F.: Sociedad Mexicana de Antropología.

Lines, J. A. (1943). Bibliografía antropológica aborigen de Costa Rica. San José: Facultad de Letras y Filosofía, Universidad de Costa Rica.

Lines, J. A. (1967). Bibliografía antropológica aborigen de Costa Rica. San José: Tropical Science Center.

Ribeiro, G. L. (2008). Cosmopolíticas, poder e teoría em Antropologia. En: E. O. Garbulski (comp.), Actas del Primer Congreso Latinoamericano de Antropología (pp. 51-79). Rosario, Argentina: Universidad Nacional de Rosario.

Marín, M. (2001). Desarrollo de la Antropología Urbana en Costa Rica en las dos últimas décadas del siglo XX. San José: Departamento de Antropología, Escuela de Antropología y Sociología, Universidad de Costa Rica (Manuscrito inédito: Curso Seminario de Autores II).

Martin, G. (1942). Guía de la Universidad de Costa Rica. Anales de la Universidad de Costa Rica, 4.

Meléndez, C. (1957). Legislación indigenista de Costa Rica. México: Instituto Indigenista Interamericano.

Meléndez, C. y Duncan, Q. (1972). El negro en Costa Rica. San José: Editorial Costa Rica.

Molina, I. (2008). La influencia del marxismo en la historiografía costarricense. A Contra Corriente, 5(2), 220-236.

Murillo, C. (1995). Identidades de hierro y humo. La construcción del ferrocarril al Atlántico 18701890. San José: Editorial Porvenir.

Murillo, C. (1996). Antropología e identidades en Centroamérica. San José: Departamento de Antropología, Escuela de Antropología y Sociología, Universidad de Costa Rica.

Murillo, C. (2000). Hacia una Antropología pertinente para la Centroamérica actual. Cuadernos de Antropología, 11, 7-13. 
Murillo, M. (2008). Estado actual y perspectivas de la investigación arqueológica en territorio costarricense. En L. G. Jaramillo (coord..), Arqueología en Latinoamérica: Historias, formación académica y perspectivas temáticas. Memorias del Primer Seminario Internacional de Arqueología Uniandes (pp. 4184). Bogotá: Ediciones Uniandes.

Murillo, M. (2011). Precolumbian Social Change in San Ramon de Alajuela, Costa Rica. University of Pittsburgh Memoirs in Latin American Archaeology No 22. Pennsylvania: University of Pittsburgh Center for Comparative Archaeology.

Otárola, F. (2001). Los estudios de la mujer y la Antropología en Costa Rica. Inédito. San José: Departamento de Antropología, Escuela de Antropología y Sociología, Universidad de Costa Rica (Manuscrito inédito: Curso Seminario de Autores II).

Programa Estado de la Nación en Desarrollo Humano Sostenible. (2011). Cuarto Informe Estado de la Región Centroamericana en Desarrollo Humano Sostenible 2010. San José: Programa Estado de la Nación-Región.

Quesada, F. (2007). La modernización entre cafetales 1880-1930 (Tesis doctoral inédita). Instituto Renvall, Universidad de Helsinki, Helsinki, Finlandia.

Revista de los Archivos Nacionales de Costa Rica. (1942). Año VI, (5 y 6, mayo-junio): 307-319.

Revista de Ciencias Sociales. (1984 (1), 1985 (2), 1987 (3)). Ediciones Especiales de Antropología: Tendencias actuales de las investigaciones en Antropología. Universidad de Costa Rica.

Revista Vínculos (1975). Revista de Antropología del Museo Nacional de Costa Rica, Vol. I (1).

Rodríguez, O., Guevara, M. y Román., D. (2014). La Antropología costarricense en contexto: Réquiem por el exotismo. Ponencia presentada en Universidad del Cauca y en Jornadas de Investigación, Laboratorio de Etnología. En prensa. (O. Rodríguez, Guevara, M. y D. Román, comunicación personal, mayo, 30, 2014)

Rovira, J. (2000). Los orígenes de la sociología como una ciencia social en Costa Rica y la contribución de Eugenio Fonseca Tortós. En J. Rovira, J. L. Vega y F. Bolaños (eds), Eugenio Fonseca Tortós. Selección de su obra sociológica (Tomo III, pp. 821-897). San José: EUCR-EUNED Editorial Universidad de Costa Rica-Editorial Universidad Estatal a Distancia.

Seminario de Integración Social Guatemalteca. (1959). Integración social en Guatemala, Vol. II (Series: Seminario de integración social guatemalteca, no. 9). Guatemala: Ministerio de Educaión Pública

Stone, D. (1956). Biografía de Anastasio Alfaro González. San José: Editorial Atenea.

Stone, D. (1961). Las tribus talamanqueñas de Costa Rica. San José: Museo Nacional, Ministerio de Cultura, Juventud y Deportes.

Tristán, J. F. (2007). Diario de arqueología de José Fidel Tristán. San José: Museo Nacional de Costa Rica.

Zúñiga, R. (2001). La Antropología costarricense en la última década del siglo XX: Un aporte subjetivo. San José: Departamento de Antropología, Escuela de Antropología y Sociología, Universidad de Costa Rica (Manuscrito inédito: Curso Teoría y Práctica de la Antropología Sociocultural en Centroamérica). 


\section{Anexo I: "IV Congreso Costarricense de Antropología"}

Resumen: Incluimos esta reseña del "IV Congreso Costarricense de Antropología", celebrado en la UNED, del 6 al 8 de diciembre de 2005, debido a que, a diferencia de los otros congresos nacionales de Antropología, y por diversas razones, este no contó con una memoria.

Este Congreso trató temáticas como estudios urbanos, sociedad contemporánea, genética de poblaciones, globalización e identidad, salud, medio ambiente, género, juventud, religión y otras. Lo organizaron la Universidad de Costa Rica, el Museo Nacional, el Ministerio de Cultura Juventud y Deportes y la Asociación Costarricense de Antropólogos (ASOAC). Vale mencionar que la colaboración de ASOAC incluía fondos recogidos por los miembros para este Congreso que sin embargo no se utilizaron en él, por lo que el presidente de la Asociación los entregó para la preparación del Segundo Congreso de la Asociación Latinoamericana de Antropología, organizado por el Departamento de Antropología en la UCR. Fue una importante colaboración para este otro evento que contó con amplísima asistencia nacional e internacional, cuya comisión coordinadora estuvo formada por Ana Cecilia Arias Quirós, Olga Echeverría Murray, Margarita Bolaños Arquín, Floria Arrea Siermann y María Eugenia Bozzoli Vargas.

En el IV Congreso, se realizaron simposios sobre estudios arqueológicos efectuados en diferentes sitios del Valle Intermontano Central, en el sur de Centroamérica y en la cuenca media del río Sarapiquí. El Congreso fue dedicado a don Luis Ferrero Acosta, a la Profesora Janina Bonilla Pignataro, a la Dra. Eugenia López-Casas, al Dr. Ronald Chaves Cárdenas y al Dr. Michael Snarskis.

A continuación, otros datos amablemente proporcionados por la profesora Echeverría Murray, Coordinadora del IV Congreso y directora del Departamento de Antropología de la Universidad de Costa Rica en la fecha de este encuentro.

Unidad Académica Base: Escuela de Antropología y Sociología. Departamento de Antropología.

Ubicación Geográfica: El IV Congreso Costarricense de Antropología se llevó a cabo en las instalaciones de la Universidad Estatal a Distancia (UNED) en Sabanilla, cantón de Montes de Oca, San José, del martes 6 de diciembre al jueves 8 de diciembre de 2005 .

Instituciones Colaboradoras: Ministerio de Cultura, Juventud y Deportes; Museo Nacional de Costa Rica; Asociación Antropológica Costarricense (ASOAC); Asociación de Estudiantes de Antropología.

Realizaciones concretas del proyecto de acuerdo con objetivos y metas: Se alcanzó el objetivo general al cumplir con "generar un espacio de discusión sobre las transformaciones socioculturales de Costa Rica 
en la actualidad y los retos para la antropología y la arqueología". Esto por cuanto se abrió un espacio para que los profesionales e interesados en la disciplina antropológica se reunieran y se promoviera un debate nacional sobre el quehacer del antropólogo y el arqueólogo en nuestro país.

Se cumplió la meta de tratar de consolidar cada vez más los Congresos con esta iniciativa de realizarlo bajo la coordinación del Departamento de Antropología en esta oportunidad y de crear un espacio de análisis y discusión de los principales problemas socioculturales del país convocando a la comunidad de Antropólogos a exponer sus trabajos de investigación, acción social y docencia en este espacio. También se cumplió el objetivo de fortalecer la comunicación entre los investigadores y la consolidación de la antropología y la arqueología.

Cambios cualitativos y cuantitativos atribuidos al proyecto: La diversidad de áreas temáticas como: antropología, sexualidad y género; genética de poblaciones; antropología, religión y magia; nuevos enfoques en arqueología; antropología, salud y medio ambiente; antropología y educación; Guanacaste descubrimientos más recientes en arqueología; antropología, literatura y lingüística; museología; antropología urbana, sociedad y actualidad; antropología, cultura y desarrollo; entre otros, marcaron el carácter analítico de la actividad al reflejarse a través de las diferentes ponencias la importancia actual de los problemas investigados sobre la realidad sociocultural actual y pasada.

Ponencias: El número de ponencias recibidas ascendió a un total de 104 (ciento cuatro). Algunas de ellas fueron:

1- San José siglo XXI: Dinámica del capitalismo e imaginarios urbanos. Carmen Araya Jiménez.

2- Algunos resultados de las investigaciones biológicas en la ejecución del PGA del PH. Cariblanco. Juan Carlos Villegas Arguedas.

3- Antropología Social, arqueología y gestión: una alianza necesaria. Karla Jinesta y Ma Laura Villalobos.

4- Investigaciones arqueológicas recientes en el sitio P-254 Sector Finca 6, Delta del Diquís, sureste de CR. Badilla, Corrales y Artavia.

5- Análisis FODA en la Asociación UCANEHU, Talamanca, Costa Rica. Róger Martínez Castillo.

6- Los Higuerones: un sitio con mucha historia (A-272LH). Abraham Zúñiga Jiménez.

7- La Tuberculosis y el Sanatorio Carlos Durán en Costa Rica: 1915-1940. Vivian Solano Brenes.

8- Negativos en el Consumo. Melvin Valverde Solano.

9- El museo de la UCR: hacia su definición y consolidación. Arias, Barboza, Carranza y Zavaleta.

10-Religión y modernidad en una comunidad costarricense. Pablo Céspedes y Daniel Pacheco.

11-Foros de información y discusión por Internet como instrumento para la triangulación de información. Marisela Navarro Brenes. 
12-Distribución de características antropogenéticas en la población del Valle Central de Costa Rica. Paula Morera y Bernal Morera.

13-Aproximación genealógico-genética a la primera fase Del mestizaje en Costa Rica Bernal Morera y Ramón Villegas.

14-Estimación de la mezcla genética en la población de Nicaragua. Bernal Morera.

15- ¡Jesa Buey!, variedad en el vocabulario del boyeo. Giselle Chang Vargas.

16-Aprendizajes metodológicos y conceptuales de género y etnia a partir del I foro de mujeres afrodescendientes de la provincia de Limón. Diana Fuster y Valeria Varas.

17-Cambio versus continuidad en la propuesta del Movimiento de la Iglesia Católica Reformada. Cindy Valverde y Luis Walter.

18-Los desastres naturales: buscando el culpable. Nicole Sault.

19-Ritos funerarios católicos en el Valle Central de la CR del siglo XIX. Patricia Fernández, Manuel Chacón.

20-Cerámica ahumada en Guanacaste: Murillo Aplicado un tipo de producción costera Felipe Solís y Anayensy Herrera.

21-Procesos del trabajo lítico en el sitio Manzanillo durante la Fase Orso de la Bahía de Culebra. Anayensi Herrera y Felipe Solís.

22-La evolución cultural del poblamiento precolombino del Valle Central de Costa Rica (eje ciudad colón - tabarcia). Raquel Ornat Clemente.

23-El vestido tradicional de los Borucas. Uriel Rojas. 